Article

\title{
South American Expert Roundtable: Increasing Adaptive Governance Capacity for Coping with Unintended Side Effects of Digital Transformation
}

\author{
Gabriela Viale Pereira ${ }^{1,7, *}$, Elsa Estevez ${ }^{2,3}$, Diego Cardona ${ }^{4}\left(\mathbb{D}\right.$, Carlos Chesñevar ${ }^{5}$, \\ Pablo Collazzo-Yelpo ${ }^{6}$, Maria Alexandra Cunha ${ }^{7}{ }^{\circledR}$, Eduardo Henrique Diniz ${ }^{7}$, \\ Alex Antonio Ferraresi ${ }^{8}$, Frida Marina Fischer ${ }^{9}\left(\mathbb{D}\right.$, Flúvio Cardinelle Oliveira Garcia ${ }^{10}$, \\ Luiz Antonio Joia ${ }^{11} \mathbb{D}$, Edimara M. Luciano ${ }^{12}$, João Porto de Albuquerque ${ }^{13} \mathbb{D}$, \\ Carlos O. Quandt ${ }^{14}\left(\mathbb{D}\right.$, Rodrigo Sánchez Rios ${ }^{14}$, Aurora Sánchez ${ }^{15}$, \\ Eduardo Damião da Silva ${ }^{14}$, João Silvestre Silva-Junior ${ }^{16}$ (D) and Roland W. Scholz ${ }^{17}$ (D) \\ 1 Department for E-Governance and Administration, Danube University Krems, \\ 3500 Krems an der Donau, Austria \\ 2 Department of Computer Science and Engineering, Universidad Nacional del Sur, B8000 Bahía Blanca, \\ Argentina; ecestevez@gmail.com \\ 3 Consejo Nacional de Investigaciones Científicas y Técnicas, B8000 Bahía Blanca, Argentina \\ 4 Facultad de Administración, Finanzas y Ciencias Económicas, Universidad EAN, 110221 Bogotá, Colombia; \\ diego.cardona.68@gmail.com \\ 5 Instituto en Ciencias e Ingeniería de la Computación, Universidad Nacional del Sur, B8000 Bahía Blanca, \\ Argentina; cic@cs.uns.edu.ar \\ 6 Department of Management, Vienna University of Applied Sciences, 1180 Wien, Austria; \\ pablo.collazzo@edu.fh-wien.ac.at \\ 7 Escola de Administração de Empresas de São Paulo, Fundação Getulio Vargas, 01313-902 São Paulo, Brazil; \\ alexandra.cunha@fgv.br (M.A.C.); eduardo.diniz@fgv.br (E.H.D.) \\ 8 Program in Cooperative Management, Pontifical Catholic University of Parana, 80215-901 Curitiba, Brazil; \\ alex.ferraresi@pucpr.br \\ 9 Department of Environmental Health, School of Public Health, University of São Paulo, 01246-904 São Paulo, \\ Brazil; fmfische@usp.br \\ 10 Corregedoria Regional da Polícia Federal no Estado do Paraná, 82640-040 Curitiba, Brazil; \\ fluvio.garcia@pucpr.br \\ 11 Brazilian School of Public and Business Administration, Getulio Vargas Foundation, \\ 22231-010 Rio de Janeiro, Brazil; Luiz.Joia@fgv.br \\ 12 Management Graduate Program, Pontifical Catholic University of Rio Grande do Sul, \\ 90619-900 Porto Alegre, Brazil; eluciano@pucrs.br \\ 13 Institute for Global Sustainable Development, University of Warwick, Coventry CV4 7AL, UK; \\ j.porto@warwick.ac.uk \\ 14 Department of Administration, Pontifical Catholic University of Parana, 80215-901 Curitiba, Brazil; \\ carlos.quandt@pucpr.br (C.O.Q.); rodrigo@sanchezrios.com.br (R.S.R.); eduardo.damiao@pucpr.br (E.D.d.S.) \\ 15 Department of Administration, Universidad Católica del Norte, 1270709Antofagasta, Chile; asanchez@ucn.cl \\ 16 Department of Medicine, São Camilo University Center, 04263-200 São Paulo, Brazil; \\ joao.junior@prof.saocamilo-sp.br \\ 17 Department of Economics and Globalization, Department Knowledge and Information Management, \\ Danube University of Krems, 3500 Krems an der Donau, Austria; roland.scholz@emeritus.ethz.ch \\ * Correspondence: gabriela.viale-pereira@donau-uni.ac.at; Tel.: +43-2732-893-2304
}

Received: 29 November 2019; Accepted: 13 January 2020; Published: 19 January 2020

Abstract: This paper presents the main messages of a South American expert roundtable (ERT) on the unintended side effects (unseens) of digital transformation. The input of the ERT comprised 39 propositions from 20 experts representing 11 different perspectives. The two-day ERT discussed the main drivers and challenges as well as vulnerabilities or unseens and provided suggestions for: (i) the mechanisms underlying 
major unseens; (ii) understanding possible ways in which rebound effects of digital transformation may become the subject of overarching research in three main categories of impact: development factors, society, and individuals; and (iii) a set of potential action domains for transdisciplinary follow-up processes, including a case study in Brazil. A content analysis of the propositions and related mechanisms provided insights in the genesis of unseens by identifying 15 interrelated causal mechanisms related to critical issues/concerns. Additionally, a cluster analysis (CLA) was applied to structure the challenges and critical developments in South America. The discussion elaborated the genesis, dynamics, and impacts of (groups of) unseens such as the digital divide (that affects most countries that are not included in the development of digital business, management, production, etc. tools) or the challenge of restructuring small- and medium-sized enterprises (whose service is digitally substituted by digital devices). We identify specific issues and effects (for most South American countries) such as lack of governmental structure, challenging geographical structures (e.g., inclusion in high-performance transmission power), or the digital readiness of (wide parts) of society. One scientific contribution of the paper is related to the presented methodology that provides insights into the phenomena, the causal chains underlying "wanted/positive" and "unwanted/negative" effects, and the processes and mechanisms of societal changes caused by digitalization.

Keywords: digital transformation; unintended side effects; proposition-based expert roundtable; trandisciplinarity

\section{Introduction}

\subsection{Contextualizing Digital Transformation in Developing and Transitioning Countries}

Digitization has been recognized as a main driver of human, socio-cultural evolution [1-3]. Digital systems are changing society by increasing connectivity, converting processes and transforming information from analog to digital. This enhances communication and interaction between people, organizations, and things, and it augments perception on all scales from the nuclear-particle level to the level of the universe. However, such change also includes a coarsening because we work with a finite set of representations that may induce unexpected errors (e.g., error propagation of different types; see [4-6]). Although it is strongly recognized that digitalization creates opportunities for enhancing social and environmental well-being, it also raises the potential sustainability challenges [1] and unintended side effects (unseens) that extend far beyond error propagation. Indeed, broad and pervasive digitalization processes present genuine features of any fundamental technology innovation, with intended positive but also unintended negative effects. Thus, based on the concept of triangulation, such processes should be analyzed based on different perspectives trying to identifying where the rebounds are and to finding causal-effect relationships among them. Such analysis should contribute to identify positive and negative unintended side effects, what we call in this paper as unseens.

The present paper provides the key messages of a South American expert roundtable (ERT) on structuring research on sustainable digital environments. This roundtable has been the third in a sequence of regional science ERTs on this topic starting in Japan [7] and Europe [2], to be followed by the present South American ERT and Indian, North American, and African ERTs in 2020/21. A basic idea is that diverse world regions are differently prepared and equipped to maintain viability and/or leadership in the current digital transition. As outlined in the carefully prepared workbook for the South American ERT [8], this paper aspires to develop an overarching structure of unseens related to the digital transformation and the world's regions - here, for South America—and to provide ideas for transdisciplinary processes for coping successfully with such a transformation. 


\subsection{Adaptive Governance Capacity for Developing Socio-Technical Innovation}

The idea of vulnerability management $[9,10]$ relates prospective systemic risk management to a system's adaptive capacities to adapt if something negative (and unexpected) has occurred (such as with many impacts of the digital transition). Thus, improving the adaptive governance capacity of sensitive stakeholder groups and subsystems of a region for developing sociotechnical innovation is an acutely important means of global, regional, and local sustainability management. The need for adaptive governance approaches, multistakeholder discourses, and transdisciplinary discourses has also been discussed in the frame of global Sustainable Development Goals (SDGs) [11,12]. Different views of the best governance strategies for developing digitized economies and managing digitization processes and consequences [1] include, for instance: resisting preemptive regulation and promoting favorable conditions; central governments taking an active role in shaping the direction and softening negative consequences of digitalization; and a passive governing process in which government leaves industries to innovate while it builds capabilities for addressing resulting social and environmental damage.

Taking a critical look at digitalization governance strategies, we may distinguish between [1]:

(i) a laissez-faire, industry-driven approach; an open-market-based approach that relies on a market's ability to organize and protect itself in the face of threats; and limited government intervention;

(ii) a precautionary and preemptive strategy on the part of a government to avoid or prevent exposure to irreversible threat and mitigate risk in the immediate future; and

(iii) a stewardship and "active surveillance" approach by government agencies to reduce risks derived from digitalization while promoting private-sector innovation.

We may take the European Union's (EU) strategy as an example. In the course of privatization of digital infrastructures [13], the EU had long followed a laissez-faire approach; yet, the EU is known for high standards in the field of civil and human rights when ensuring privacy and safety and empowering the economy (for instance when introducing the General Data Protection Regulation (GDPR; see EU, 2018) or Article 17(2) of the EU Charter of Fundamental Rights, which considers personal data as personal property).

\subsection{Goals of the South American ERT (Proposition-Based)}

Digital technologies are transforming all domains of economic, sociopolitical, (bio-) technological, environmental, and other systems and have provided groundbreaking beneficial innovations. Until now, much research has focused on the development and implementation of digital technologies, yet little attention has been given to reflecting on and anticipating the unseens of such technologies, although they have the potential to endanger systems and structures that are considered valuable and that contribute to the resilience of sociotechnological systems.

The goals of the South American and previous Japanese and European ERTs have been (1) to identify positive or negative unseens linked to digital transitioning; (2) to reflect on the way(s) in which unseens can best become subjects of science in an overarching way; and (3) to project, from the science perspective, which unseens might become the subjects of transdisciplinary science, i.e., practice discourse that relate different types of knowledge in order to efficaciously master complex, relevant societal challenges [14].

\section{Theory}

\subsection{Mechanisms on Unseens}

The concept of unseens was developed in systems theory. Feedback loops are seen as general patterns of living systems; they represent circular causalities. Feedback loops can cause instability, chaotic behavior, bifurcation, and delayed, dislocated, and other unintended side effects. Coping with unintended side effects is a major element of sustainability learning [15]. Argyris [16] applied Forrester's [17] loop feedback theory to double loop learning. One loop, the primary feedback loop, 
includes the primary objectives related to an activity, however any action has unintended side effects, such as a bee's energy consumption when it seeks nectar. This is called the secondary feedback loop. Nuclear waste and accident management, for example, may be seen as unseens, rebounds, or boomerang effects stemming from the production of nuclear energy. Yet there are also positive side effects, e.g., the use of DNA information for criminal analysis may be considered a positive side effect.

The digital transition has led to a wide range of unseens. The Japanese ERT [7] discussed concerns ranging from the loss of privacy, shifting realities, and Western cultural imperialism via new relationships with machines (falling in love with computers/robots) to cyberterrorism, digital oligarchy, and a digital economic divide. When we talk about mechanisms' unseens, two factors are important. First, what is unintended and what constitutes negative or positive impacts depend on a specific perspective given by an analysist, organization, country, or other human system or stakeholder. This is related to the issue of sustainability including a normative component that is assigned according to the values, norms, objectives, etc. of the stakeholders involved. This, in turn, is related to the stance that the mechanisms underlying the digital transition are based on drivers of human actors when using and developing digital technologies and of properties of social systems such as market mechanisms.

For instance, human beings aspire to improve the economy, seeking to pay the lowest price possible, which is, at best, no cost at all. Thereby, internet users are willing to provide personal data to digital search engines providers such as Google or to social media such as Facebook. These global companies are driven to survive in the market or to gain leadership worldwide, and one smart business option is to market its users' personal data to business, political, or other actors. This, in turn, may result in loss of privacy, which-at least in Western cultural settings-is considered an unintended side effect. As the present paper takes a sustainability perspective, unintended negative side effects of South American stakeholder groups are in the foreground of analysis, although what is positive for one stakeholder group may be negative for another.

An increasing set of scientific inquiries are analyzing, describing, and explaining mechanisms that are causing unseens $[18,19]$. We present several of these to provide a scaffold for relating the propositions of the South American ERT to general trends and mechanisms.

The main message of the European ERT [2] was that the option to generate, transfer, store, process (compute), retrieve, and use digital data seemingly ubiquitously is fundamentally changing the world's economic system. The smart use of digital data, $D$, is supplementing the classical economic key variable labor, $L$, capital, $C$, and natural resources, $R$. Thus, the genesis of economy or gross domestic products, $G D P$, has changed from

$$
G D P=f(C, L, R) \rightarrow G D P=f(C, L, R, D)
$$

This may have immense impacts if countries, companies, or other human systems are not owners of digital technology resources. As they are (widely) immaterial and can be transferred at low cost to centers for storage, these systems cannot participate in the value chain, as, for instance, the profits made by the use of tools and services of automatization [20] are made abroad. This results in increasing the digital divide for developing countries in a critical manner.

Whereas the Industrial Revolution substituted machine energy for human (and biotic) energy, the digital transition allows for replacing human cognitive operations with those accomplished by computers. From a phylogenetic perspective, this is even more fundamental than the change of the economic system. A proposition of the Japanese ERT is that we may have to redefine humanity. If we reflect on evolutionary drivers, we may postulate about evolutionary competition (such as the current economic power game), about curiosity, or about convenience. With respect to the last, Gottfried Wilhelm Leibniz (1646-1716) promoted the development of the digital $\{0,1\}$ number system and constructed one of the first mechanical computers because he was bored by the tedious calculations needed for his modeling and theory building [21]. Thus, we may argue that convenience and the outsourcing of labor may be seen as drivers, but in addition, military and political power have become digitized, as evidenced by China's surveillance society [19]. 
Global networking has become an essential property of and vision of the digital world since Berners-Lee's 1989 World Wide Web (WWW) (www, [22]) project. We are facing a kind of global brain or nervousnet-like supersystem that may be conceived as "the self-organizing, adaptive network formed by all people on this planet together with the information and communication technologies that connect them into a cohesive system" [23]. However, this vision has nearly become a nightmare. Data is being used for social surveillance. The integrity of web based media is discussed, including the misuse of fake news. Under the term "cyber sovereignty," Russia, China, and several other states such as Egypt have stepped out of the global network. Examples such as the global discussion on internet standards for the Internet of Things [24] demonstrate that digitalization, also from a technology perspective, means more than having access to cell-phone signals. The digital transition is complex and includes disruptive effects and power games on many levels, which makes South America, as a subcontinent of the Americas, vulnerable with respect to the digital transition. Identifying and ordering these vulnerabilities and unseens is the main objective of this paper.

\subsection{Impacts of Digital Transformation and Innovations in Economy and Society}

To gain a more in-depth understanding of the impacts of digital transformation and innovations in the economy and society, in the following, we illustrate with some examples. The global deployment of networked cameras, sensors and other digital artifacts produce an impressive amount of data. Such volumes of data combined with algorithms applying artificial intelligence (AI) enable automated systems to perform diverse complex tasks, historically performed by human beings. For example, cameras and sensors can replace security personnel; autonomous vehicles can reduce the need of human-operated vehicles, meaning the disappearance of taxi-drivers; robots can replace warehouse workers; automated algorithms applied for government-decision making processes can reduce the number of civil servants. As another example, formerly genuine human services such as language translation, legal advice, and first health services will be replaced by appropriate and efficient digital services entirely conducted through the use of computers. In a digitalized future society characterized by increased productivity it is expected that workers' labor will be more valuable and the goods produced relatively less costly. In addition, in such digitalized contexts, also observed is mass amateurization. For example, journalists are replaced by bloggers and influencers [25]. Observing such changes, at a first glance, there are two linked major rebound effects. The first is the loss of workplaces mainly in routine, activity-based jobs [26] that comprise a larger share of employment in developing countries than in developed countries. The second linked major rebound effect is that buying more with less money will increase material consumption, with resulting severe negative impacts on climate change from deforestation, loss of biodiversity, mineral resources management, and greater waste (recyclable and non-recyclable production), among other non-environmental friendly effects $[27,28]$.

We do not know how rapidly current business models will be reshaped and/or jobs replaced, when major changes will occur, and when consequential opportunities will arise [3]. Yet, a critical question reads: Will the unavoidable loss of considerable numbers of well-established jobs be outweighed by newly created jobs? Desirable societal effects of smart digitization involve the growth of employment (IT industries, new IT-based business opportunities) and increased productivity (workers' labor being more valuable) [3].

Optimistic digital futurists go further, citing Herbert Simon's 1965 statement: “Machines will be capable, within twenty years, of doing any work a man can do" [29]. The optimists postulate artificial intelligence-based human substitution in activities that require high levels of cognitive skills and an increasing share of the work of high-level decision-makers being accomplished by machine-supported decision-making. Therefore, digitization processes may hit knowledge-based business models and cognitive workers as hard as-or even faster-than non-knowledge business models and manual workers. New work opportunities, whether employment or freelance, will undoubtedly emerge, and even if digitization results in a net loss of jobs, welfare will not necessarily be negatively affected by the change as it may be linked to the old [30]—and new — discussion of unconditional basic income [31]. 
Theoretical reflections on digitalization, partly from a South American perspective, have shown that fundamental functions of society such as labor, citizenship, basic components of economy, education, and also governance are transformed by digital technologies. From a developing and transitioning country perspective, education may pave the avenue to better development, but we may also argue that agile management calls for solid, reliable governmental framings as fundamental transitions of social systems take decades. As the big five of digital industry-namely, Alphabet Inc., Amazon, Apple, Facebook, and Microsoft, and Alibaba have much control over how the Internet works in different countries, nation states have limited control over the Internet. The big five are more than global business players. They must be considered as global infrastructure providers. Thus, the providers of basic and universal infrastructure cannot be compared to enterprises such as Coca-Cola or Mercedes. Their impacts, global reach, capacity to provide portfolios of universal information technology services, their possession of explicit and implicit knowledge, and influence empower them to impact in what way a country may participate in the internet-cloud-based generation of value. Whether and how this may develop cannot be forecast or predicted. This holds true particularly for information and communication technologies (ICT) for development [32]. Sahay et al. [32] refer to complexity, uncertainty, and new challenges such as the above-mentioned fundamental changes as research challenges. However, as scientists, decision-makers, and the public at large participate in the venture, for instance, in transdisciplinary learning processes, we may think about the ways in which sustainable projects may help strengthen developing countries.

2.3. Science-Practice Collaboration and the Vision of a Transdisciplinary Process Following the Legal Aspects of How a Particular Solution will be Adopted and How Users will Benefit from It

Designing solutions for the type of multidimensional and multifaceted problems that communities face today requires the collaborative efforts of scientists from multiple disciplines working in close collaboration with practitioners and policy makers who understand the problem details and possess primary data. In particular, the need for science-practice collaboration is underpinned by the following arguments. Practitioners encounter, are able to recognize, and have experience with real world problems. Scientists know theories, methodologies, and tools for designing solutions, which can later be tested and refined in authentic settings by practitioners. This is expressed in Figure 1. Transdisciplinary processes organize societal learning processes to develop socially robust orientations for sustainable development [14]. Socially robust means that the orientation includes scientific state-of-the-art knowledge (represented by the upper lens in Figure 1), the results from integrating and relating science knowledge (i.e., academic rigor) and best knowledge from science (i.e., experiential wisdom), whereby not only the uncertainty but also the ignorance of human knowledge are acknowledged, and that the constraints of the study become transparent [15]. As sustainable transitions include normative issues, the multistakeholder discourse (bottom lens in Figure 1) should include representatives from all major stakeholder groups involved in the transdisciplinary process. We present the core of transdisciplinarity, and propose that the ERT should initiate a transdisciplinary process based on one of the most pressing challenges identified by it.

Particularly in South America, universities deliver skillful professionals and researchers to societies. However, compared with the developed world, countries in the region lack: (a) the ability to generate data and process it efficiently, (b) the capacity for translating research results into development instruments, (c) the capacity for knowledge transfer and exchange and brokerage platforms to facilitate them, and (d) incentive instruments and mechanisms for promoting research-practice collaboration. In addition to addressing the previously mentioned gaps, science-practice collaboration could contribute finding new ways to generate, utilize, transfer, and integrate knowledge, aiming at fulfilling the development goals of our communities. 


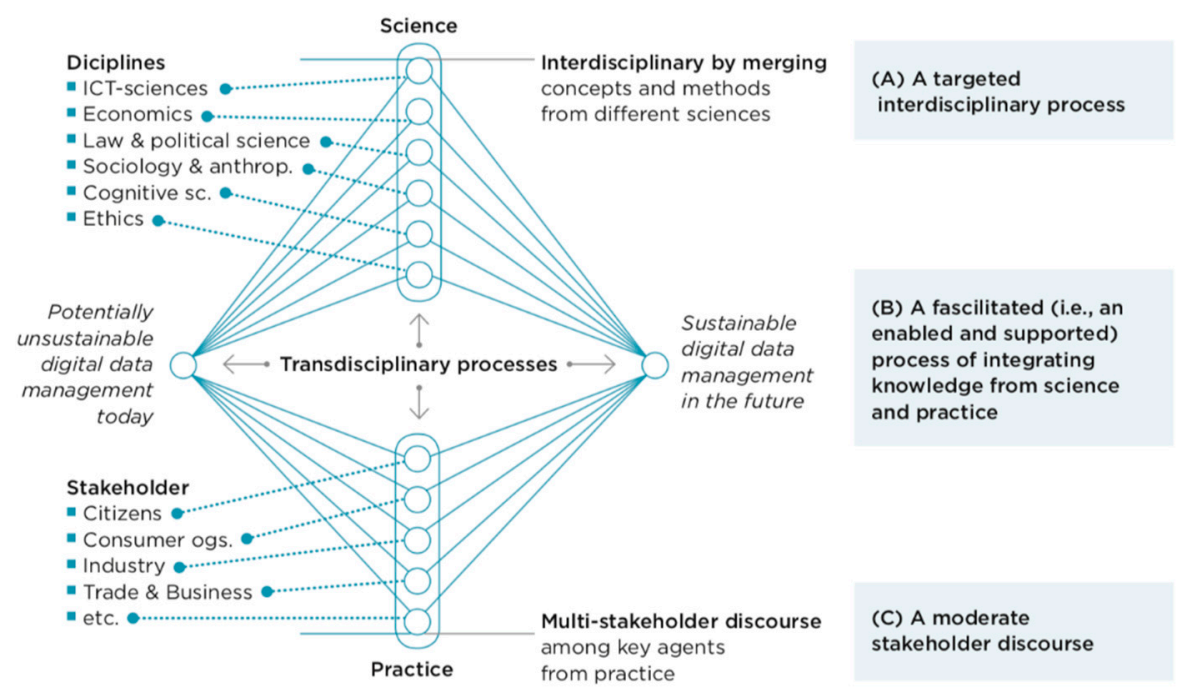

Figure 1. The three major subprocesses of a transdisciplinary process (adapted from Scholz and Le [33]).

The method proposition-based ERT can be viewed as (i) a means to draw attention and to prepare scientists for participating in the targeted transdisciplinary process (see Figure 1) and (ii) as a problem-structuring tool. The idea of problem structuring was developed in soft operational decision research [34-37] and was applied and adjusted for transdisciplinary processes [38,39]. The proposition-based ERT was developed in the course of the 2017 Japanese ERT [7] and the 2018 European ERT [2]. We could learn from the Japanese ERT that scientists focusing on unseens of the digital transition may be viewed as a kind of triangulation. The analysis of the propositions allowed for getting compatible views on types of risks, threats related to global AI applications, and specifics of the Asian-Japanese culture. The European ERT went one step further. It initiated a transdisciplinary process based on the key message. This messages states that major unseens from the digital revolution result from insufficiently understood relations between ownership, economic value, access, and use of digital data. Based on this message, the large-scale project "The Responsible Use of Digital Data as the Subject of a Transdisciplinarity Process" (DiDaT; [40]) was initiated in 2018 in the exact way it has been described in Section 3.1 [40].

\section{Methodology}

\subsection{The Methodology of Proposition-Based Expert Roundtables}

A team of scientists from Danube University (Scholz, Parycek, and Viale Pereira) contacted researchers working in the sustainability and digitalization fields (Ferraresi [co-organizer], Estevez, Luciano) at South American universities for co-hosting the ERT. The perspectives (see Table 1) were first identified by the organizers (Ferraresi, Scholz, Viale Pereira, Collazzo, and Damião) and adjusted through a phone chain. The perspectives are a kind of triangulation of systemic prospects/layers of the digital transition. Finally, 20 scientists representing five South American countries (see Table 1) provided 39 propositions on relevant unseens of the digitalization in South America (see Appendix A) related to 11 perspectives. Intensive preprocessing (with multiple revisions) took place in the construction of the proposals, due mostly to the new perspective of not focusing on the positive (intended) prospects but rather on the impacts of secondary feedback loops. Based on this process, a "Workbook for Preparing the South American Roundtable Structuring Research on Sustainable Digital Environments" was prepared, including the propositions of Appendix A. All participants received the workbook a week before the ERT was to convene. 
Table 1. Perspectives and science experts (all experts whose names are followed by a + participated in the ERT ${ }^{1}$ and the proposal; experts with a * only provided propositions).

\begin{tabular}{|c|c|c|}
\hline No. & Perspective & Experts (Country) \\
\hline 1 & Digital Infrastructure & E. Estevez $^{+}(\mathrm{AR})$ \\
\hline 2 & Artificial Intelligence & C. Chesñevar ${ }^{+}(\mathrm{AR})$ \\
\hline 3 & The Dark Side of ICT & L. A. Joia ${ }^{+}(\mathrm{BR})$ \\
\hline 4 & Rebounds of Smart Cities & M. A. Cunha ${ }^{+}(\mathrm{BR}) \&$ J. P. Albuquerque (BR) \\
\hline 5 & Economic Change & A. A. Ferraresi ${ }^{+}(\mathrm{BR}) \&$ C. Quandt ${ }^{+}(\mathrm{BR})$ \\
\hline 6 & Industrial Change & P. Collazzo-Yelpo ${ }^{+}(\mathrm{UR})$ \\
\hline 7 & Big Data in Occupational Health & F. M. Fischer ${ }^{+}(\mathrm{BR}) \&$ J. S. Silva-Junior * $(\mathrm{BR})$ \\
\hline 8 & Digital Democracy & D. Cardona ${ }^{+}(\mathrm{CO}) \&$ A. Sanchez ${ }^{+}(\mathrm{CH})$ \\
\hline 9 & Cybercrime & D. R. S. Rios ${ }^{+}$(BR) \& F. C. O. Garcia * (BR) \\
\hline 10 & Corruption & E. M. Luciano ${ }^{+}(\mathrm{BR})$ \\
\hline 11 & Banking \& Cryptocurrency & E. H. Diniz * (BR) \\
\hline
\end{tabular}

1 The ERT was moderated by R. W. Scholz (AT) and G. Viale Pereira (AT/BR). + Experts who participated in the ERT and provided propositions. * Experts who only provided propositions. Country References: AR-Argentina, BR-Brazil, UR-Uruguay, $\mathrm{CO}$-Colombia, $\mathrm{CH}$-Chile, AT-Austria.

To clarify the main concepts of the first two perspectives, we introduce the following two definitions. Digital infrastructure refers to foundational services-like fixed broadband Internet, mobile broadband Internet, Internet coverage and others-constituting the information technology capabilities of a country, region, or city enabling citizens and businesses to benefit from access to information. Artificial intelligence is defined as the automation of activities associated with human thinking, which include decision-making, problem solving, and learning [41].

The idea for proposition-based ERTs is that the science experts provide three to five basic propositions related to the three key questions described above (Section 1.3), with a maximum of 300 words and a maximum of 10 key references for understanding the scientific roots. All participants were asked to thoroughly work through all of the propositions prior to the ERT, to think about how their own propositions are related to the others, and to focus on specific and generic mechanisms generating the unseens involved in the proposition.

The two-day ERT took place in Curitiba, Brazil, on 9-10 August 2018. Participants included 12 of the authors of the propositions and the first and last authors of this paper as moderators. After a brief (five-min maximum) presentation of the background, the key, and potentially hidden general messages, each set of proposals (accessible to participants in the workbook) was discussed for 30-40 min to develop a deeper understanding of a specific perspective message. The experts had been informed of the highlights of the Japanese and European ERTs by mail before the ERT in Curitiba. The main steps of this proposition-based ERT is presented in Figure 2. 


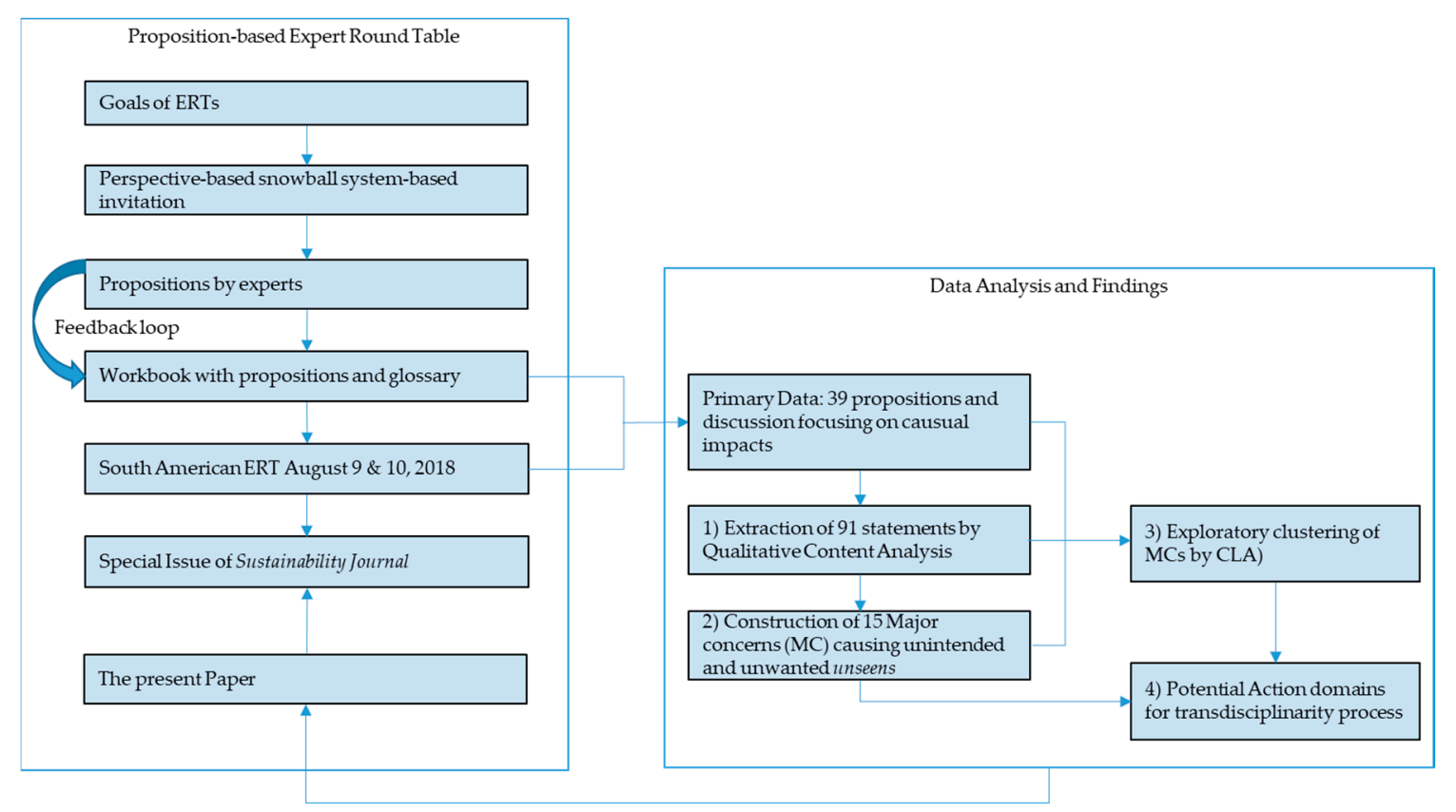

Figure 2. Steps of the South American expert roundtable (ERT) on increasing adaptive governance capacity for coping with unseens of the digital transformation, adapted from [European ERT; [2]].

\subsection{Data Analysis: A New Form of Clustering the Mechanisms of Unseens}

We describe the steps of the content analysis (including the numbers of input data and variables/missing values without referring to contents in this section). The 39 propositions and the comments made in the two-day workshop are the primary data; the comments focused on mechanisms, i.e., causal reasoning schemes that explain how a specific unseen may be explained. These arguments were recorded and discussed by the first and last authors and validated with proposal providers. We have to mention that three propositions on banking and cryptocurrency (see Table 1, No. 11) were not discussed at the ERT. The causalities were extracted from the text of the proposition.

Based on this, the first and the second authors identified 91 statements on positive drivers, barriers/challenges, and vulnerabilities/Unseens. Following the common procedure of qualitative content analysis [42], 15 main concerns (MCs) were developed from these 91 statements when describing key mechanisms of unseens discussed in the ERT. The main concerns make reference to 76 statements. An average description of an $M C$ consists of 125 words. Three paths were chosen for exploring and structuring the main conclusions, for instance, as the basis of (later) ranking their importance.

First, in order to describe the mechanisms underlying major unseens, (i) a description of the drivers and barriers for each proposition was elaborated (Section 4.1). Further, (ii) when taking a system theory perspective, the unseens and vulnerabilities were classified into three main categories (CF: contextual factors; SO: society; IN: individuals) based on their nature or their impact.

Second, we applied a cluster analysis (CLA), i.e., a semi-quantitative structuring tool to better understand relationships among the causal relationships of the causalities identified in the propositions and those involved in the main concerns. The data for the CLA were causal mechanisms, which have been included both in the propositions and the MCs. The first two authors identified these mechanisms. Thus, a table of the 39 propositions and the 15 main concerns was built (Supplementary Table S1). The rating by the first two authors identified 76 common mechanisms. For running a CLA a code 1 was chosen if a mechanism has been identified and code 0 otherwise. This allows applying the automatized CLA classification. We took the Ward Algorithms and Euclidean distance (which is identical to the number of matches, as we took only a zero, one rating, which indicated whether joint causalities could be identified for the propositions and main concerns related to the cells of the table/matrix). As CLA 
was applied in an exploratory manner, we used the Ward Algorithm as it usually provides the most distinct separation of clusters.

Third, a set of eight potential action domains for transdisciplinary follow-up processes (see Section 3.1) were identified by carefully looking at communalities of the main concerns from a policy perspective.

\section{Results}

\subsection{Drivers and Challenges/Barriers Identified in the Proposals of South American Experts}

This section describes the identified (see 1 of the right box in Figure 2) positive drivers and challenges of digitalization in the different perspectives taken (Table 1) considering both the specificities of Latin American countries (compared to other regions of the world) and the characteristics of developing and emerging economies.

The concept of digital infrastructure (addressed by E. Estevez; all names refer to Table 1) was analyzed considering three main dimensions: ICT deployment (policy context infrastructure and connectivity), government capacity, and digital literacy (human skills) (P1; P1-P39 refer to the propositions in the Appendix A). In general, digital infrastructure has the potential to "enable access and information sharing, collaboratively creating new knowledge and delivering personalized services" (P2). However, there is an exceptionally low population density in most parts of South America, which makes the market unattractive for ICT companies, increasing the challenge of broadband coverage and costs. Another identified barrier is the late response from governments as regulators, resulting in a scenario of oligopolistic digital power (P3).

Disruptive technologies have a potential for significantly changing the way governments and companies are delivering services and products to end users. The successful deployment of disruptive technologies such as artificial intelligence (AI) (C. Chesñevar), big data, and the Internet of Things (IoT) requires a systematic analysis of the overall system landscape, which demands a systematic and holistic approach. Concerning AI applications, new business models have emerged as well as paradigms that allow for compliance with users' needs such as the "ubiquity of Agreement Technologies (AT) that covers autonomy, interaction, mobility, and openness" (P4) as a way to mitigate the challenges related to lack of transparency and awareness of the final users. AI-based tools and related recommendation capabilities have the potential to "simplify users' choices" (P5) in a scenario of growing information and new possibilities of the digital world. This aspect is challenged by the dynamics of users' preferences, lack of trust, the potential for manipulation, and provenance, which influence the reputation of the recommendations. In this sense, the use of IoT as sensors and as a source for decision-making has different consequences. It can be considered positive when used for "building digital public opinion about 'everything'" or negative when referred to "monitoring urban behavior" (P6). Therefore, redefining ethical issues and social contracts is among the greatest challenges for the use of AI, especially in the public sector.

The dark side of ICT (L. A. Joia) perspective addressed three main aspects of the digital transformation: the impact of ICT in developing countries, the phenomenon of social media and popular movements, and the effects of smartphone use on mental health. Regarding the first aspect, the "ICT potential for development of developing countries" (P7) and the challenge of overcoming the significant gap in access opportunities between Latin American countries and EU countries was emphasized. This argument aligns with that of Walsham [43], who questioned the real impact of ICTs for development and how to extend their benefits and mitigate the so-called side effects, for instance, of the rich/poor and global divide. The second point addresses social media and popular movements as drivers for "listening to 'unheard' voices in the society" and promoting "new forms of collaboration and interaction" (P8). However, the promised freedom of smartphones can easily be transformed as a form of "slavery" (P9) as a consequence of self-reinforced social dependence of the individual citizen on smartphone news [44]. 
When bringing digital environments to the city level, smart cities (M. A. Cunha and J. P. Albuquerque) emerge as a way to address the growing phenomenon of urban areas and the consequent problems that emerge from this expansion. In a context of complexity and connectivity of the society, smart cities require the deployment of multiple information systems and applications in a comprehensive, innovative, and integrated way, which relates to the digital infrastructure perspective. The main barrier includes the technological lock-in on a citywide scale as a consequence of the "disparities of competences" and "maintenance costs of the technological infrastructure" (P10). There is a potential for smart cities to foster digital participation and citizen empowerment by "engaging citizens in the process of data production" and "establishing appropriate modes of engagement between citizens, government and digital technologies" (P11). This possibility comes with structural barriers related to the lack of conditions for critically engaging with digital technology by large parts of the poor and marginalized population, which may limit effective participation to wealthy and homogeneous societal groups, while large parts of the population may have their roles constrained to act as simple sensorial devices that capture (mostly predefined) data, implying the instrumentality of digital participation (P12).

The economic change (A. A. Ferraresi and C. Quandt) perspective brings the discussion to the impacts of the global trend in automation that, on one hand, is seen as a driver for economic growth but, on the other, has consequences such as the "growing unemployment rate of low-qualified human resources and difficulties adapting to changes produced by a digital world" (P13). The fact that knowledge is a strategic resource for enhancing prospects for productivity growth increases the digitalization labor divide because of the "high negative impact in regional productivity and profitability of less-developed regions unable to follow the trends" (P14). Digital property rights also bring a challenge to the appropriation of digital resources, such as data, and their economic value in the digital world, especially in defining ownership of intangible/dematerialized resources (P15). In the context of the labor force, there is, on one hand, the universal access to information as a driver and, on the other, the lack of digital readiness due to a delay in restructuring educational programs and professional education in the region to provide effective qualifications for responding to the digital transition and dealing with transdisciplinary capabilities (P16). The analytics provided by technology leave part of the society behind, affecting certain segments/strata of society that will not find employment. Digitally disrupted economies emerge as an opportunity for new business models and wealth creation and, at the same time, represent a disruption of traditional manufacturing and services (P17), which—without the correct regulatory frameworks - results in a scenario of oligopolistic digital power (P3). Finally, digital transformation also affects specific sectors, such as digital or smart agriculture, having as drivers new opportunities for increased rural productivity due to new technologies and, as its main challenge, the transformation of the role of local farmers in the supply chain dealing with genetic diversity and the sustainability of small farms.

Industry 4.0 (P. Collazzo-Yelpo) is changing the decision-making capabilities in firms, allowing for a more accurate, responsive, and flexible process due to real-time access to data and the faster spread of information (P20). The challenge of building these capabilities is fundamental to avoid the consequent Industry 4.0 divide among small and large companies and among countries globally distributed.

On the perspective of big data in occupational health (F. M. Fischer et al.), three main aspects were discussed: disclosure of work-related diseases and work injuries (P22), digital data analytics and early functional aging (P23), and the payment of social security benefits and public policies (P24). The disclosure of data in occupational health has the potential to raise "awareness about safety and health at work and provide data for evidence-based policy making, which supports the design of improved health-promotion programs and prevention of work-related diseases/injuries" (P22). The drivers of digital data analytics include the "prevention of excluding workers associated with early functional aging and the possibility to keep experienced workers active" (P23). The main barrier relates to the quality and accuracy of data as a consequence of open access, which is due to the underreporting of events and bias when reporting work-related illnesses (P22, P23). This is particularly true in relation to professions with a high risk for accidents, which may receive biased 
data. There is also an ethical dilemma on the social justice dimension in regard to the balance of public accounts of national social security systems, which require transparency on the use of public funds for paying social security benefits and citizens' awareness about possible deficits (P24). This discussion is extended to the private sector (for instance, with the emergence of DNA analytics) and the use of open data related to health and safety at work for higher health insurance rates.

Digital infrastructure, in particular connectivity, is among the drivers for promoting digital democracy (D. Cardona and A. Sanchez). Appropriate connectivity contributes, on one hand, to the increased visibility of public matters, trust in public administration, and improving the control of public administration and, on the other hand, facilitates access to information and interaction with citizens (P25). However, the challenge is to provide connectivity with the most appropriate technologies, instead of incurring the costs of expensive (the latest) solutions (P25). The digital revolution has the potential to redefine democracy with increased possibilities of "mobilizing people for societal changes and increasing community awareness about world issues" (P26). However, digital media are challenging the existing sociotechnical configurations and cultural contexts that may affect the truth and the trust in societies to deal with populism, political polarization, far-right or far-left extremism, radicalization, waves of hate against women and minorities, post-truth, and fake democracy [45]. At the same time that social media have become critical to promote social attention and engagement, facilitate information sharing, coordinate social movements' activities, and exchange emotional information, they have generated a "new form of civic activism that may jeopardize traditional structures and the whole social system" (P27). The pervasive effect of the potential reduction of information asymmetry has also become a challenge as a source of distortion on the equilibrium of many systems, including the structure of society at all levels (P28). Finally, when discussing this aspect from a public sector perspective, digitalization was seen as promising for democratizing the benefits of the digital society, but it has become a challenge to fulfill the high investments of electronic government initiatives (P29).

The roundtable also included context-specific perspectives such as cybercrime, corruption, and cryptocurrency. In the context of cybercrime (R. S. Rios and F. C. O. Garcia), the digital world has been challenging existing institutions with new forms of criminality (P32) that extend beyond the borders of a nation and its jurisdiction. The challenges include the transnational nature of cybercrime (P31) and the fact that existing laws cannot always predict every possible aspect of a crime (P30). There is a lack of specific knowledge, for instance, on dealing with multi and interconnected offenses that have to be merged (P32).

The perception of corruption (E. M. Luciano) approached the topic in relation to the level of administrative burden in countries, which, in Latin America especially, is considered very high [45]. Sometimes, efforts to reduce administrative burden are too heavily focused on technologies [46] instead of on organizational processes. Decision-making focused on technology more than on its suitability for the organizational processes can increase the presence of segregated and stand-alone solutions in governmental agencies (P33). In countries with high levels of state bureaucracy, laws, rules, and procedures are numerous and sometimes disconnected or overlapping, thereby increasing the occurrence of over- or under-regulated situations [46]. In this context, there is a risk of making changes without the necessary discussion and without considering all the inherent complexity and focused only on giving fast answers to the pressures of civil society. This situation can lead to under-regulated situations, which can, paradoxically, increase corruption (P34). It is necessary to develop a state's capacity for decision-making and governance focusing on long-term planning decisions. Among the challenges is to define adequate anti-corruption practices considering context-specific social-cultural-behavioral aspects (P35). Another aspect is that corruption has been redefined by digital transformation, and although digitalization increases the digital trail, new forms of corruption have emerged in the digital world (P36).

The perception of banking and cryptocurrency (E. H. Diniz) has an important role in explaining the field of digital payments and understanding the evolution of complementary currencies. One particular driver of the adoption of complementary cryptocurrencies is to develop the local economy at 
the time of financial crisis, with the emergence of "neighborhood currencies" or "social currencies" (P37). The adoption of cryptocurrencies creates a new mechanism for rewarding users for their loyalty. However, the implementation of blockchain technology and the use of fidelization strategies for positive citizen engagement are considered major challenges (P38). Finally, the perspective addresses the challenge of expanding the use of cryptocurrencies and ensuring their stability (P39).

\subsection{Unseens Discussed in the South American ERT and Main Groups of Causalities Resulting in Unintended and Unwanted Unseens}

This section presents the unseens or the vulnerabilities identified as part of the 39 propositions contributed by experts that were further enriched through the discussions maintained during the ERT conducted in Curitiba (originating 15 Major Concerns). According to their nature and based mainly on their impacts, we classify them into three main categories (of impacts on): context factors (CF), individuals (IN) and society (SO). The list of unseens, the references to the proposition in which they were identified, and the category in which they were classified are presented in Table 2.

Table 2. List of Identified Unseens.

\begin{tabular}{|c|c|c|}
\hline Unseen & Prop & Type \\
\hline Low population density & P1 & $\mathrm{CF}$ \\
\hline Low capacity and weak government institutions & P1 & CF \\
\hline Psychological warfare & P2 & IN \\
\hline Digital curtain imposed by internet giants & P3 & $\mathrm{CF}$ \\
\hline Users' perception/acceptance & P4 & IN \\
\hline Need for improved recommendation and explanation capabilities & P5 & IN \\
\hline Use of "black-box" algorithms & P5 & IN \\
\hline Digital image versus information flow among cities' ecosystems & P6 & SO \\
\hline ICT development reinforcing socioeconomic gaps & P7 & $\mathrm{SO}$ \\
\hline Crises of representation & P8 & $\mathrm{CF}$ \\
\hline Homo digitalis & P9 & IN \\
\hline Delusion of democratization & P12 & SO \\
\hline Weakening government institutions & P12 & SO \\
\hline Governments in the region lack the ability to adapt & P13 & $\mathrm{CF}$ \\
\hline Increasing inequalities & P14 & SO \\
\hline Dematerialization of wealth production & P15 & CF \\
\hline Lack of adaptation of educational systems & P16 & $\mathrm{SO}$ \\
\hline Creating and strengthening monopolies/oligopolies & P17 & CF \\
\hline Further inequalities in the labor market & P17 & SO \\
\hline Small farmers becoming powerless & P18 & SO \\
\hline Genetic manipulation of farm products & P18 & SO \\
\hline Bias in reporting data about work-related diseases/injuries & P22 & CF \\
\hline Fewer opportunities for young workers & P23 & $\mathrm{SO}$ \\
\hline Social exclusion as a consequence of the rigors of health assessments & P24 & SO \\
\hline Misuse of information due to intentionally poor data quality & P24 & $\mathrm{CF}$ \\
\hline Misuse of public funds & P25 & $\mathrm{CF}$ \\
\hline Manipulating citizens' opinions in social media & P26 & $\mathrm{CF}$ \\
\hline Manipulating protests & P27 & $\mathrm{CF}$ \\
\hline Jeopardizing traditional institutions & P27 & $\mathrm{CF}$ \\
\hline Ubiquity of users of digital platforms may exhibit a lack of understanding of local community needs & P27 & $\mathrm{CF}$ \\
\hline $\begin{array}{c}\text { Raising awareness about socio-economic gaps between countries distorts the equilibrium of many } \\
\text { systems }\end{array}$ & P28 & $\mathrm{CF}$ \\
\hline Increasing inequalities & P29 & SO \\
\hline Identifying the offender and place of operation; which jurisprudence? & P30 & $\mathrm{CF}$ \\
\hline Lack of admissibility of evidence in court & P31 & $\mathrm{CF}$ \\
\hline Underestimated growth of complementary cryptocurrencies & P36 & $\mathrm{CF}$ \\
\hline Crypto-engagement of customers as new mechanisms for citizen engagement & P37 & CF \\
\hline The potential of stable cryptocurrency & P38 & CF \\
\hline
\end{tabular}

Based on a preliminary analysis of the 39 propositions on 11 perspectives, the two-day ERT in Curitiba on August 9 and 10, 2018, and continuous interactions between the experts, the first and second authors composed 15 unseens or critical phenomena caused by the digital transition in South 
America (Box 1). This was done when referring to the 76 single causalities, labeled major concerns (MCs). For each MC, a qualitative description of factors and causalities is provided.

Box 1. Major concerns, highlights, messages, hot spots, and lessons of the SA ERT on Sustainable Digital Environments.

(MC1) Global digital divide-The region is characterized by challenging terrain including mountainous areas, jungles, and a vast territory, presenting severe disadvantages for ICT deployment. Thus, new market mechanisms need to be envisioned to generate opportunities for attracting private sector investments. It is expected that such investments should be able to overcome the current high costs of deploying new digital infrastructure in the region, to counterbalance the high costs of ICT resources compared with other regions of the world, and to bridge the gap that this region and its countries face compared to developed countries in terms of connectivity, e.g., international internet bandwidth per user. The current conditions represent barriers for development since lack of access to information precludes workers from equipping themselves with capacities they need to improve their opportunities for employment and to exercise their right to be aware of work-related diseases and injuries, among other negative consequences.

(MC2) Identifying vulnerable groups-The region and each country in it have different types of vulnerable groups, each presenting specific needs. Governments should first know who they are; second, understand each group's particular needs; and third, design programs to promote their social and economic inclusion, contribute to developing their capacities, and ensure that they are neither discriminated against nor manipulated by outsiders.

(MC3) Lack of government capacity-Current scenarios are delivering complex new challenges for governments. For example, they are pressed to define new regulations governing how we interact in the digital world; they face a continually changing environment pushed by internet giants; they are urged to make decisions based on advice from technology oligopolies, while at the same time, they need to build trust in weakened traditional government institutions. A common feature in the region is the lack of government capacity in various areas, including a lack of qualified human resources and in-house know-how, scarce financial resources, hierarchical organizational structures that resist change, and rigid and complex regulatory and legal frameworks. New governance models, including acquiring capacity by partnering with external stakeholders, can help strengthen their capacities.

(MC4) Digital Literacy/Inequality-There is a lack of proper conceptualization and understanding of what digital literacy means, particularly considering the local context and its different communities. Governments need to identify and understand the readiness of their communities. They need to analyze the underlying causes of digital inequality and properly assess the differences between poor/underprivileged and rich/educated groups and define policies and programs designed to bridge the gaps.

(MC5) Social media has the power to jeopardize democracy-Social media and its massive use by society contribute to amplify messages among people who have similar ideas, therefore, contribute to social polarization. Citizens' opinions appearing on the internet are not under the control of any responsible institution that could be liable for the published information. Citizens do not have the capacity to assess what digital information is meaningful and reliable. Moreover, many times, their trust is abused by fake news. The digital literacy of citizens, and particularly those competencies needed to identify fake news, activists, or trolls, is too low for participating in reliable democratic processes and dialogues online.

(MC6) Data as the new currency-At a time when big data is available for almost every sector and both private and public sectors are benefiting from their exploitation, the value of data is of utmost relevance. On one hand, citizens are relinquishing personal data to big IT companies or simply publishing their private data on the open domain. Mostly, they are unaware of the consequences of making their data available online and how others might use it for their own advantage and profit. On the other hand, new mechanisms for sharing and accessing data are providing opportunities for new business models in different sectors, e.g., health, tourism, trade, and culture, among others. Such models are associated with benefits for some actors but also with damages or losses for others. There is a critical need to assess and openly account for who benefits and is empowered by the use of open data and personal data shared on the internet and how this data contributes to new development models.

(MC7) Trust in unknown virtual sources of information-The source of ICT/Google-based information is evolving rapidly and in unpredictable ways. There is experimental evidence (see Montag and Diefenbach, Towards Homo digitalis (Ref. 1)) that people tend to unknowingly believe in seemingly personal, independent, algorithmic recommendations more than in someone's personal recommendation. Thus, the unseen of missing/delayed adaptation may induce harm. There is an increasing amount of information and speed of information flow (partly in a self-organizing process) on social media. Reinforcing algorithms in the digital curtain/social media is preventing the access of diverse information, and unaware citizens are consuming information depicting only part of-but definitely not all—dimensions of the real world. 
Box 1. Cont.

(MC8) Rebounds of smart cities and spatial transfer-Pushed by current trends, important cities in the region are investing significant resources in developing smart-city initiatives. In many cases, the initiatives raise ethical dilemmas between functional management aspects of smart cities and stakeholder demands, like the risk of gentrification. Several Latin American cities have a configuration of a central region, sometimes including the municipality, a commercial area, and wealthy neighborhoods, surrounded by pockets of poverty and vulnerability. Besides "pushing" people to peripheral regions, smart-city initiatives may also be pushing problems into marginalized regions and creating unseen challenges for the most vulnerable communities.

(MC9) Digital readiness-Countries in the region face the challenge of not having a critical mass of human resources equipped with the digital competencies required to adapt and succeed in new economic models, like the industrial revolution 4.0 and knowledge societies. There is a retrospective reaction and a prospective dimension with respect to this mechanism/causal chain. The retrospective reaction refers to the management of the current situation and the need to develop mechanisms and incentives for educating and retraining people to acquire new skills. The prospective dimension refers to the reform of primary and secondary education, in particular for children relying on public education.

(MC10) Bias on data-driven decision making-Since 2009, when President Barack Obama signed the Memorandum on Transparency and Open Government (Ref. 2), government agencies have been engaged in a race to make their data available. This has also pushed the private sector, non-governmental and international organizations, and other actors to disclose data. In many cases, the released data lack quality, and their publication is biased since only selected data are released while other related important data are not. When such data are used by professionals involved in high-risk operations or governments in evidence-based, policy-making processes, their decisions can result in severe risks and in negative consequences to individuals and large communities.

(MC11) Mitigating corruption-Despite the significant investments in digital government made by governments around the world, and lately in open government that aims to promote transparency and accountability, there are still unfulfilled yet promised benefits from those efforts. Most countries in the region are ranked poorly in the corruption perceptions index (Ref. 3), which shows corrupt practices in the public sector. According to Transparency International, the main reasons include weak institutions, efforts to undermine free and independent media, control of civil society and international organizations, and increases in conflicts of interest and private influence, among others (Ref. 4). Particularly related to digital technologies, governments do not have the needed human, organizational, and institutional capacities to stand up to and counterbalance the power of IT monopolies, who attempt to impose their own solutions and business models, regardless of the principle of prioritizing the public good.

(MC12) Global companies versus local industries and small and medium enterprises (SMEs) - According to the Organization for Economic Cooperation and Development (OECD), in emerging-market economies, like those in South America, small and medium enterprises (SMEs) are responsible for up to $45 \%$ of jobs and up to $33 \%$ of national GDPs, and when the informal sector is included, some estimates are that SMEs contribute to $90 \%$ of total employment (Ref. 5). Based on this and considering the fulfilment of the Sustainable Development Goals (SDGs), such as SDG \#8-promoting inclusive and sustainable economic growth, employment, and decent work for all; and SDG \#9-promoting sustainable industrialization and fostering innovation, SMEs and local industries constitute major enablers. However, in the region, they lack the capacities to compete with global companies; they are shut out of the market due to lock-in policies and procedures from technology providers; and they do not benefit from owned digital platforms. In addition, in most cases, they are unprotected by national and regulatory frameworks.

(MC13) Acceptance of autonomous decision-making-Public and private institutions are increasingly relying on artificial intelligence tools to serve customers, for example, using chatbots to respond online to users' questions $24 \mathrm{~h}$ a day, seven days per week; and to implement autonomous decisions in information systems, for example, using an algorithm relying on machine learning to select applicants for a job vacancy. Two main risks associated with the adoption of new technologies include bias in automatic decision-making processes and discriminatory practices adopted after selective training of the tools. The criteria for autonomous decision-making processes should be transparent, and "black box" behavior (algorithms making decisions based on unknown or untraceable rules) should be avoided, particularly in government services.

(MC14) Ethical dilemmas-Since digital technologies are now embedded in most of the activities that persons perform in their daily lives, special attention should be paid to ethical issues arising from the use of new technologies. Examples of ethical dilemmas include defining responsibility when decision-making is performed autonomously by a software program, manipulating public opinion through online fake news, handling local issues through lenses imposed by global issues disseminated through the internet and social media, and externally influencing local leaders using digital means for creating chaos, among others. When making decisions related to ethical dilemmas, we must consider that ethics is directly linked to culture and, therefore, agreed upon according to the norms and principles of the local context. 
Box 1. Cont.

(MC15) Legal systems-Digital transformations affecting how individuals interact with each other and with private and public institutions are having profound impacts, which, in most cases, are very difficult to foresee or even estimate in advance. In addition, many of them happen without the proper and necessary legal bases to legitimize how they are being conducted. This observation is valid beyond the South American context since it is observed worldwide. However, in this region, particularly, most countries need to adjust their legal frameworks to specify precisely what is allowed and what is forbidden regarding the use of new technologies. Furthermore, it would be desirable to have an integrated regional view regarding country-specific legal frameworks, such as the General Data Protection Regulation (GDPR) adopted by the European Union. Adopting an integrated regional approach for legal systems is a critical matter considering that data can be easily moved across country borders and that what is illegal in one country may be legal in another. Thus, competitive advantages are gained by some countries to the detriment of others. Without the proper legal systems in place, there is a remarkably unbalanced power relationship between common citizens and internet giants, and moreover, the failure of governments to fulfill their responsibilities regarding the protection of citizens' rights is exposed.

Ref. 1: Towards Homo Digitalis: Important Research Issues for Psychology and the Neurosciences at the Dawn of the Internet of Things and the Digital Society. Available online: https://www.mdpi.com/2071-1050/10/2/415 (accessed on 10 November 2019).

Ref. 2: President's Memorandum on Transparency and Open Government - Interagency

Collaboration. Available online: https://www.whitehouse.gov/sites/whitehouse.gov/files/omb/memoranda/2009/ m09-12.pdf (accessed on 10 November 2019).

Ref. 3: Corruption Perceptions Index 2018. Available online: https://www.transparency.org/cpi2018 (accessed on 10 November 2019).

Ref. 4: Americas: weakening democracy and rise in populism hinder anti-corruption efforts. Available online: https://www.transparency.org/news/feature/cpi-2018-regional-analysis-americas (accessed on 10 November 2019).

Ref. 5: Unlocking the potential of SMEs for the SDGs. Available online: https://oecd-development-matters.org/ 2017/04/03/unlocking-the-potential-of-smes-for-the-sdgs/ (accessed on 10 November 2019).

\subsection{Cluster Analysis}

Given a coding and choice of distance measurement algorithm, the hierarchical CLA is a proven exploratory structuring tool (see Section 3.2). Figure 3 presents the ways in which the MCs are related to the domain-specific propositions (see the $\mathrm{Y}$ axis). There is no unanimous rule on what threshold of the distance has to be taken in CLA. We took the distance threshold 10 for identifying clusters because lower threshold would provide unrobust clustering (in the sense that few changes of the ratings would result in a different clustering). Admittedly, this is a rough form of ordering as the CLA does not consider the type of causality but just whether a joint causality is identified in the proposition and the MCs. Nevertheless, Figure 3 helps in problem structuring.

The CLA presented in Figure 3 suggests the following interpretation. Cluster A comprises four major societal impacts. These are smart cities'/regions' rebounds (1), the threat of platform economics on $S M E s$ and the economic value of data (2), digital readiness (3), and global legal systems and corruption (4). Three clusters involve people's and decision-makers' specific capabilities and ways for coping with digital technologies. These are the genesis of the digital divide and the (poor) digital literacy of South American countries, which are related (Cluster B). The acceptance of autonomous decision-making tools and bias due to digital data show similar origins and/or impacts. Thus, the process of opinion formation in a digital world calls for special attention (Cluster C). Cluster D comprises social media (and its threat to democracy), vulnerable groups (which are often victims of discrimination), and the (naïve) trust in unknown digital data, which are all related to ethical dilemmas. Finally, Cluster E includes governmental capacity, seen as a highly specific general context factor that may be involved (as it is uncorrelated) in all MCs. 


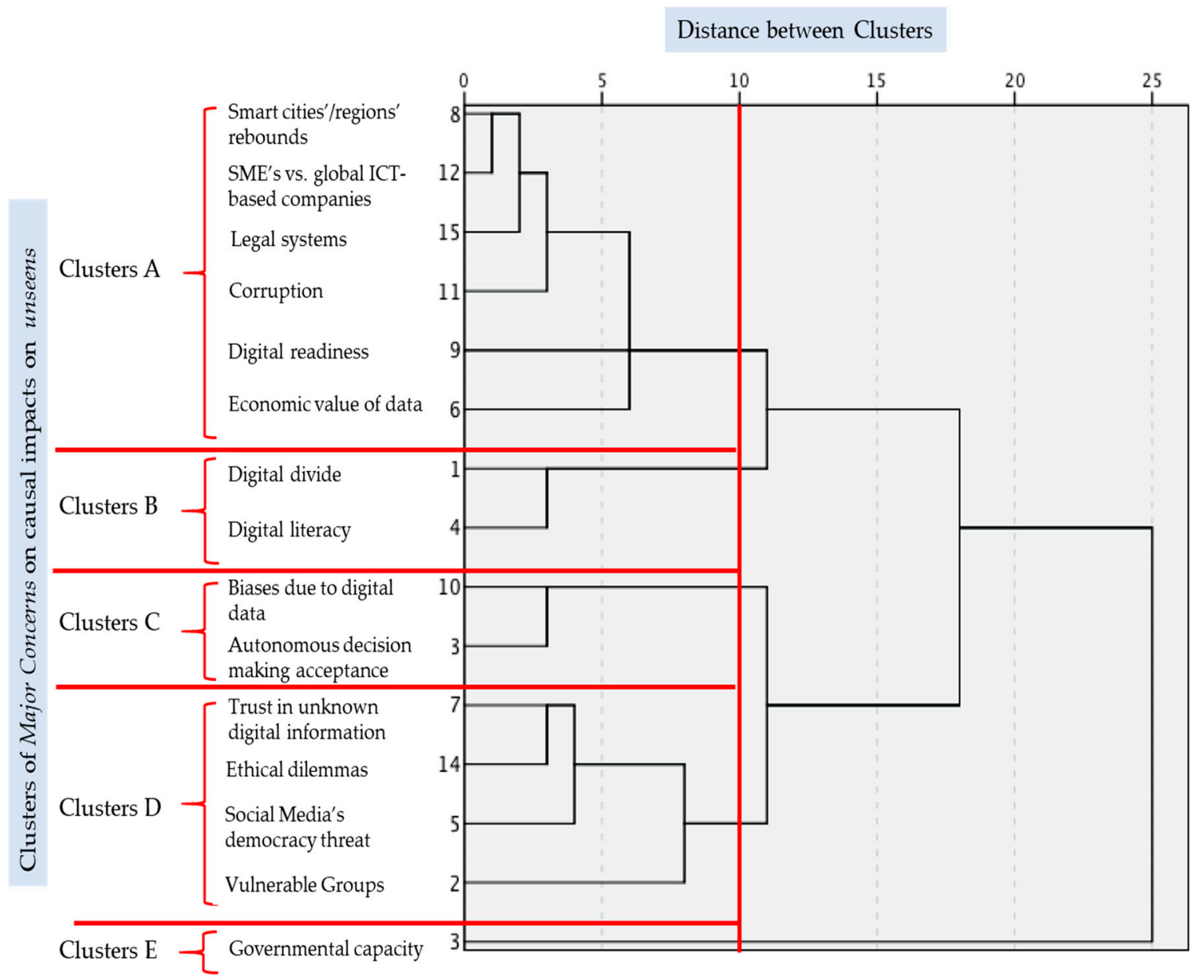

Figure 3. Clustering of the 15 mechanisms.

\subsection{Initiating a Transdisciplinary Follow up Process in Brazil}

By the end of the ERT, the majority of science experts were suggesting that a transdisciplinary process should focus on corruption (MC11). The rationale was that corruption has the nature of a specific, societally relevant, complex, and ill-defined problem whose management may benefit from transdisciplinary processes. Thus, in November 2019, E. Luciano and R.W. Scholz presented the outcomes of this paper, e.g., to 27 staff members of the Senate in Brazil, to 45 members of the national Regional Digital Transformation Group, to a group of 4 members of the federal secretary of Brazil, and to 59 planning-related members of the State of Rio Grande do Sul. The presentation included, first, the features of the proposition-based ERTs and of transdisciplinarity as methodological approaches for sustainable transition management; second, a detailed outline on how a project for the mitigation of corruption as a subject of a transdisciplinary process (MitiCo; [47]) might be conducted, and third, an overview of seven salient unseens that are expected to be of specific interest for Brazil. These seven extracted points are strongly related to the clusters, yet they were presented in a way that enabled the practitioners to gain insight into the range of unseens linked to the digital transition. Thus, the practitioners were introduced to the principles and outcomes of a transdisciplinary process.

Given the definition of the MCs, the grouping by CLA, and specific demands expressed on the following seven focus areas identified: (I) Mastery/ownership of digital data and algorithms are the basic resources of societal wealth (digital data as a new currency; see MC6). As, unfortunately, Alphabet, Amazon, Apple, Facebook, Microsoft, and Alibaba are the owners of these resources (MC12), strategies for retaining developmental autonomy are needed. (II) South America/Brazil is, most presumably, a loser in the digital divide (MC1) as it is a late adopter and has difficult geographic infrastructures that call for 
expensive inclusion via high-performance transmission systems. (III) As the value chain is changing, the question emerges whether small- and medium-sized entrepreneurs (i.e., SMEs, which account for $33 \%$ of South America's jobs) and digital entrepreneurs have a reasonable chance of survival in the Brazilian economic system (MC12). We may face a platform economic lock-in. The promotion of clusters and clusters/networks of digital entrepreneurs might become necessary. The lack of governance structure, which is dependent on the advice of oligopolies (MC3), may also cause problems. Further, (IV), corruption (MC11) is a main barrier to economic and social development. As digital communication transforms how communication is conducted, corrupt activities may become more traceable. Yet, certain digital technologies (browsers) may make tracing corruption more difficult. Therefore, corruption in a digital world includes a demand for new or adjusted legal systems (as may be taken from Cluster A). (V) The rebounds of smart cities and spatial transfer (MC8) are issues because (a) functional management may not meet stakeholder demands; (b) the so-called smart city is a "middle class" concept and pushes those who are "poorer" to the fringes (e.g., through gentrification), thereby increasing the spatial inequalities between wealthy and poor urban areas; and (c) the high costs of changing digital municipal infrastructure and lack of local technical know-how may cause unwanted lock-ins. (VI) As the value chain is being transformed, the question emerges whether SMEs (comprising 33\% of the jobs) and digital entrepreneurs have a reasonable chance to survive in the Brazilian economic system (MC12). We may face a platform economic lock-in, and the promotion of clusters and clusters/networks of digital entrepreneurs might become necessary. Finally, (VII), South America is also suffering because the global phenomenon of social media (including political bots) is jeopardizing democracy (MC6); digital readiness is lacking (MC9). Such a process benefits when a targeted disciplinary process can be organized according to the mechanisms described in the MCs.

The analysis and the transdisciplinary approach were unanimously appreciated in all meetings. The suggestion to conduct the MitiCo project on corruption was welcomed. However, the key representatives asked science for collaborative processes in other domains as well, such as increasing the adaptive capacity of SMEs (III), identifying and managing rebounds of smart cities (V), or mitigating the unwanted impacts of social media use (VII).

\section{Discussion}

The discussion first refers to the propositions as major elements of the ERT. Section 5.1 reflects on the constructed methodology of problem-structuring by proposition-based ERTs and subsequent transparent qualitative and quantitative content analysis on well-defined challenges of sustainable transitioning. Then, the cluster of major concerns is assigned to levels of human and sociotechnical systems (Section 5.2). Finally, Section 5.3 describes the overarching aspects of transdisciplinary processes, including potential action domains for transdisciplinary follow-up processes and a case study in Brazil.

\subsection{Methodology of Problem Structuring by Proposition-Based ERTs}

We can distinguish four major steps (see Figure 2). First, the formulation of propositions by 11 experts/expert groups. These propositions were secondly discussed with the focus on understanding causal mechanisms and interrelations. These two data, third, became subject of a content analysis and-for assuring some convergent validity, fourth, by a CLA. These rigidly standardized steps build the foundation for providing seven potential domains for initiating a transdisciplinary process. Here the selection was also affected by some constraints of the case of Brazil. The method and the results were highly appreciated in a series of interactions with administrative institutions and executive officers.

We can see two contributions of the present paper. First, we think that the presented four steps procedure may be viewed as a contribution to problem structuring methods $[34,48]$ as they have been developed in soft operational research. Second, the presented method substantiates knowledge generation in transdisciplinary processes. The input of scientists from 11 different disciplines could be integrated [49]. Thus, we can see a contribution to research- and targeted interdisciplinarity-based 
transdisciplinarity or deliberative transdisciplinarity. The presented results may be well used in the follow up processes when relating science and stakeholder knowledge (see Figure 1).

\subsection{Scientific Outcomes for Understanding the Systems}

We will subsequently discuss what unseens have been identified by the South American science experts on different levels.

\subsubsection{Aspects Related to Individual Behavior}

The individual perception that culminates in the level of trust in unknown data has been addressed in many propositions and perspectives (P2, P6, P9, on digital democracy; P26-29). Especially under the dark side of ICT perspective, the argument is that "the trustfulness and reliability of information agreements and recommender systems are questionable." The knowledge about which information should be trusted and believed [2], especially in this era of fake news-which may, in fact, be stimulated by traditional media (discussion on P28) - is considered to be a new challenge in the individual's life. In addition, the loss of privacy (e.g., when profiling a person) and the potential risk of rationalization of controversial behavior (e.g., racial profiling) may affect individuals' perceptions, trust, and acceptance of the outcomes.

The new dynamics of information, including the increasing amount and speed of information flow (P26, P20) and the reinforcing algorithms in the digital curtain of social media, are preventing a diversity of information, which, in turn, may endanger democracy. This type of digital participation or collective decision-making that includes a relatively homogeneous group of citizens may exclude vulnerable groups, thereby increasing social polarization and an inability to effectively overcome marginalization (P12). This is especially relevant for South America since the region has many vulnerable populations (the number living below the poverty limit is estimated at $40 \%$ of the population) (P2).

As emphasized by the cluster, there are also ethical dilemmas between functional management aspects of smart cities and stakeholder demands. General ethical/moral principles that buffer ethically unreasoned demands from dominant "internet collectives" (the ethical dimension of collective internet decision-making) may cause harm.

\subsubsection{The Role of Governmental Organizations}

Digitalization in the public sector follows an evolutionary process of adopting necessary capabilities and models of electronic and smart government (which refers to transformational efforts through the introduction of ICT in governmental organizations and the effort to promote stakeholder engagement), followed by the development of effective smart governance settings and the collaborative environment that characterizes them [50]. As a consequence of the digital transformation, governments are now facing new challenges that require shifts in the way they deliver public services, and this, in turn, requires a user-driven administration.

The main concern in regard to the lack of government capacity appears to be related to many propositions, perspectives, and identified unseens (Digital infrastructure-P1, P3; Rebounds of SC-P10; Economic change-role as regulator-P13, 15, 17, 18; Digital democracy-P25-P29, Corruption P33-35, and Digital currencies-P37). The main capacities include specialized knowledge and resources, both organizational and institutional. New governance models could help to strengthen their capacities. In the specific case of corruption in Brazil, digital government could be used as a tool for anticorruption practices and to fight a "cultural legacy" of corruption, which requires improving the government's capacities to take action and a multi-stakeholder process.

\subsubsection{Societies}

Societies in South America face several development challenges. The level of ICT infrastructure and connectivity in South America is low compared with developed countries; for example, the region is below the world average for fixed broadband (P1). A study conducted among 139 countries revealed 
that an increase of 10 percent in fixed broadband penetration yielded an increase in 0.8 percent in gross domestic product (GDP) per capita [51]. Thus, governments of South American nations need to invest in digital infrastructure to ensure that digital technologies do not contribute to increasing the already-existing socioeconomic gaps, i.e., by increasing economic gaps due to the digital divide. To reduce the digital divide, they also need to dedicate efforts to creating human capacity for residents to benefit from digital services, as well as capacities in local industries and SMEs that will enable them to compete in new digital markets, thus, contributing to employment and improving local community conditions (P3).

Another risk increasing socioeconomic gaps associated with new digital developments in cities is related to the gentrification processes that are occurring as a consequence of smart-city initiatives and city development (P11). In South American cities, the process reveals significantly large socioeconomic differences between residents whose good quality of life benefits from various kinds of digital products and services, while large communities living in slums in peripheral areas of these cities face severe subsistence problems. However, as another side of the coin, access to digital devices could help people in slums to frog-leap in terms of economic and social development, before physical living conditions are improved. Another major opportunity of digital transformation, particularly in the region, is the potential use of digital technologies to define new anticorruption practices that consider specific cultural aspects of the region (P35). For all of these, governments need to ensure that legal systems are revised and adapted to protect citizens as well as SMEs and local industries' rights and to make sure that these kinds of divides existing in societies are not amplified by digital transformations.

\subsubsection{The Sociotechnical Systems}

New sociotechnical systems arising from the use of emerging technologies are serving as mirrors, amplifying and clearly revealing unwanted human behaviors. For example, the use of artificial intelligence algorithms, like those based on machine learning, may use available data, which might exhibit bias existing in societies; in such cases, they will exhibit bias in their decision-making processes (P2). Moreover, if such systems are applied by governments to make decisions about eligibility criteria for providing a public service or not, or for selecting one person over another for employment, this can unintentionally discriminate against individuals (P5). In addition, intelligent systems having the capacity to make autonomous decisions may not make decisions that align with or are expected by the local culture (P4). For example, the global survey conducted by the Massachusetts Institute of Technology (http://moralmachine.mit.edu/) about decisions made by an autonomous car showed that the selected decisions vary among Eastern and Western cultures. In addition, new sociotechnical systems must realize the value of data and how it is considered as a new currency of digital economies, and in light of this, they must take into account all the actions necessary to ensure proper data management that protects the rights of those who own the data.

\subsection{Brazilian Case Study for Transdisciplinary Processes and Reorganizing Science}

The proposition-based ERT can be seen as an instrument to draw scientists' attention to the of sustainable digital environments and as a means to initiate a transdisciplinary process. This has already worked effectively with the European ERT [2], which launched the Digital Data as a Subject of a Transdisciplinary Process (DiDaT) project in Germany [40]. About 50 scientists and 50 practitioners are involved in a process of mutual learning. In fact, the model of the DiDaT project and the idea of a transdisciplinary process was unanimously welcomed at all meetings and discussions, which include approximately 150 representatives of institutions. The ERT defined and formulated a science perspective that considered what unseens might become subjects of transdisciplinary science-practice discourses that may benefit from relating different types of knowledge in order to efficaciously master complex, relevant societal challenges [14]. The first feedback of a series of interactions from the side of administrative practitioners was overwhelmingly positive. We will see whether the science community will demonstrate a similar positive reaction. As it currently appears, there is emerging knowledge on the processes, 
dynamics, and impacts of the digital transition on different scales. The bottleneck, rather, seems to be the preparedness of science for transdisciplinary processes, and this may hold true not only for South America. Finding a sufficient number of scientists who are able to facilitate a transdisciplinary process, who can go beyond their inner-science core activities and join a (potentially time-consuming) process of mutual learning with practice, and who have the institutional and financial resources to participate, co-manage, and co-lead transdisciplinary processes is, unfortunately, both challenging and rare. We hope that this will change, for instance, by institutionalizing sustainability science and research at the level of the university.

\subsection{Strengths and Limits of the Presented Method}

The proposition based ERT is based on the idea of triangulation by perspectives. We invited science experts from five different South American countries to provide written propositions (of a certain format [8]. Naturally, the mode of selection (first list and phone chain were done by three authors) may cause bias or exclude some important issues though there is transparency of defining perspectives and propositions. The selection of the 91 key statements and their condensation to $15 \mathrm{MCs}$ by two authors embodies the subjectivity of any content analysis. The grouping of the CLA includes these uncertainties, i.e., the cluster formation has been based on whether statements between MCs were identified in the same propositions (and thus also perspectives). The weakness of the method is that it is subjective and exploratory and best allows for face validity. Its strength is that provides a transparent problem structuring for unseeens of the digital transformation.

The current analysis of the ERT went further than the European ERT. This has been due that the expert discussion on the propositions did not only focus on similarities among propositions but focused on the identification of causalities. Thus, the definition of the unseens in Section 4.2 (and "Figure 2") were enriched by the causal arguments. Yet, a formal methodology what causal factors should be included when is missing. For instance, the lack of Legal Systems is a major concern (MC15) but simultaneously a causal factor of lack of government capacity (MC3) and of global companies endangering smes (MC12). The authors suggest that causality analysis underlying the MCs such as between the MCs should be developed and included in the proposition-based ERTs. Nevertheless, the present method and paper presents a structuring of the overly complex multitude of unseens. We could learn also from the Brazil follow-up transdisciplinary process, which this structuring supports in the communication of mitigating unseens.

\section{Conclusions}

In this paper, we present the main messages of a South American Roundtable (ERT) on the unintended side effects of digital transformation. Based on 39 propositions from 19 experts representing 11 different perspectives, a two-day ERT discussed the main drivers and challenges (presented in well-elaborated propositions), as well as vulnerabilities or unseens. The science experts provided suggestions on: (i) what the mechanisms underlying major unseens are; (ii) how rebound effects of digital transformation may become the subject of overarching research in three main categories of impact: development factors, society, and individuals; and (iii) a set of potential action domains for transdisciplinary follow-up processes.

Among the contextual factors, the lack of governance capacity plays a critical role in most of the perspectives. This flaw is characterized by a low human, organizational, and institutional capacity and the lack of ability to adapt to the rapid changes introduced by digital transformations. Given the power of global IT companies, the lack of government capacity results in the dependency of governmental decisions on the advice of oligopolies that may sell technologies that have the potential to cause rebound effects in South American smart cities, as they are not sufficiently adjusted to the specific situation (e.g., strong financial and social constraints). In this context, the question also arises of who the owner is, i.e., who has access to the digital data and algorithms needed to properly participate in the global value chain and to generate societal wealth is an important factor. 
The societally related unseens are mostly negative and address mainly global challenges such as digital divides, rebound effects of smart cities, and the vulnerability of sensitive groups. The digital divide refers to the unequal development of ICT industries in developed and developing countries. Promoting smart cities may be linked to a high risk of gentrification. These conclusions hold true for Brazil and many other countries of South America. But, in addition, the urban/rural area divide can become greater when smart cities and regions are promoted. Connected to the ongoing digitalization of all (critical) infrastructures, the lack of IT governance capabilities in local government may induce a risk of technological lock-in on a city scale as changing suppliers may become very costly. Vulnerable groups may also face the challenges of digitalization, especially considering the possibility of bias in algorithms or in data, where AI applications may replicate unwanted human behaviors such as manipulation, prejudice, and discrimination.

The acceptance of autonomous decisions, together with technocratic trust and digital readiness, form the category of unseens related to individuals. A cluster-based content analysis of the propositions and related mechanisms was applied for conversion validity as an additional semi-quantitative procedure of structuring. The CLA resulted in five clusters that comprise societal impacts (Cluster A), involve people's and decision-makers' specific capabilities and ways of coping with digital technologies (Clusters B, C, and D), and a general contextual factor (Cluster E), related to the government capacity as a factor that drives or hinders (when lacking) economic and social development as an output of digital transformation.

The paper discusses general critical impacts such as the digital divide that affects most countries that are not included in key digital businesses (such as platform economics, the development of AI-based industrial and/or business innovations, or digital infrastructure development) or the challenge of restructuring small- and medium-sized enterprises whose service is digitally substituted. We also identify specific factors and effects for most of the countries of South America, such as a lack of governmental structure, challenging geography (e.g., inclusion in high-performance transmission power), or the digital readiness of (wide parts) of society. The applied method included a proposition-process ERT and a thorough content analysis using CLA as a structuring method. Thus, we consider the presented process as a problem-structuring method. This structuring is valuable, in particular, for analyzing, describing, and perhaps even developing a new field of research that we might call adaptive governance. Adaptive governance calls for not only identifying vulnerabilities and unseens. We must also understand their genesis, i.e., the constraints, causes, mechanisms, and dynamics underlying the digital transformation and, in particular, the causal chains underlying "wanted/positive" and "unwanted/negative" effects. The knowledge of these processes can be seen as a prerequisite of successful and effective transdisciplinary processes as well as strategic sustainability management and planning in the overly complex process of the digital transition.

Supplementary Materials: The following is available online at http://www.mdpi.com/2071-1050/12/2/718/s1. Table S1: Data from Experts in Digitalization.

Author Contributions: This expert roundtable has been coordinated by R.W.S. and G.V.P., and planned with support of A.A.F., E.D.d.S. and P.C.-Y. All authors (besides G.V.P. and R.W.S.) participated in the propositions writing. All authors (besides E.H.D., J.P.d.A. and J.S.S.-J.) participated in the roundtable. G.V.P., E.E. and R.W.S. worked on the content analysis of the propositions including the Cluster Analysis. The first draft of the manuscript was written by G.V.P., then modified and supplemented by E.E. and R.W.S. All authors read the complete draft and provided feedback and inputs to previous versions of the submitted manuscript and agreed on the final manuscript.

Funding: The South American Expert Roundtable received funding from the Department for E-Governance, Danube University Krems, Austria.

Acknowledgments: We thank Peter Parycek, Head of the Department for E-Governance, Danube University Krems, for providing the funding for the SA ERT, Elaine Ambrose for the thoughtful English language editing and Maria Carmen Martinez, Rodolfo Andrade de Gouveia Vilela, Luis Fabiano de Assis, Maria Regina Alves Cardoso for the contribution to Propositions on Big Data in Occupational Health.

Conflicts of Interest: The authors declare no conflict of interest. 


\section{Appendix A. Propositions on the Future Perspectives on Digital Transition}

Appendix A.1. Propositions on Digital Infrastructure: New Governance Models for Sustainable Development: Elsa Estevez

Proposition A1. On average, South America lacks the needed capacities to fully benefit from digital infrastructures (Needed ICT capacities).

Summary: Different types of capacities are needed for a society to fully benefit from digital infrastructures, such as the availability and affordability of digital devices, connectivity, human skills and public policies promoting the use of digital products. Compared with developed regions, South America needs important investments to further develop most of such capacities, and such efforts face serious challenges.

Comment: There are four types of factors enabling a community to benefit from digital eco-systems [52]: (1) infrastructure-including networks, data processing, storage facilities and devices; (2) connectivity - services enabling to connect to the Internet; (3) human skills—individual's competencies enabling the consumption of digital services; and (4) policy context-regulations contributing to developing sustainable and scalable digital solutions. Analysing the infrastructure, South America needs to improve the LTE/WIMAX coverage (the average is 69.1, while the average in Europe is 92.2, and in America as a whole is 77.4); and the percentage of households with computers (the average is 46.5, while in Europe is 79.6 and in America 64.90). Regarding connectivity, all indicators show that South America lags significantly behind Europe and America. In addition, the region is below the world average in fixed broadband (11.23 versus 12.4), the percentage of households with Internet access (42.04 versus 51.5), and the international internet bandwidth per Internet user (65.41 versus 74.5). Concerning human skills, the average in South America (6.66) is below the average of high income (8.15) and upper-middle income (6.91) countries, however it is higher than the world average (5.85). Revising the policy context, prices paid for mobile devices and connectivity in South America are almost double, except for the 1GB mobile broadband that is about 10 times more than prices paid in Europe. Considering the regional context, ensuring the needed investments for improving the regional capacities is challenging, due to: (1) vast, mountainous, and jungle territory (the total territory is 17.84 million $\mathrm{km} 2$ compared to 10.18 million in Europe) and small population (422 million, compared to 741 million in Europe), resulting in low population density (one third of Europe density); and (2) governments in the region possess low capacity and weak institutions, among others. The costs of needed ICT capacities are one reason for increasing the global digital divide related to developing countries.

Proposition A2. The contribution of digital infrastructures to sustainable digital environments can only be assessed if there is a clear understanding of how the infrastructures are empowering or disempowering people (Side-effects of digital infrastructures).

Summary: A digital infrastructure provides media to access and share information and to collaboratively create new knowledge. As an enabler of knowledge-societies, such infrastructures contribute to the empowerment and development of individuals and communities. However, in many cases, people are unaware of how much personal information they are sharing and how such information is used by the infrastructure providers for hidden purposes.

Comment: Digital infrastructures enable the provision of personalized services [53], appealing to their users based on user's data possessed by the infrastructure. For example, knowing preferences and information about their life, Facebook suggests users to link with old friends and offers selling products they like. Despite the appealing services, there are side-effects that require critical assessment. On the positive side, the infrastructure contributes to empower people through access to information and facilities for sharing user-generated content. On the negative side, infrastructure providers can 
use content provided by users against them. For instance, it is well-known how the 2016 United States presidential elections and the United Kingdom Brexit referendum have been influenced by "psychological warfare" facilitated by user's information leaked from Facebook [54]. Keeping in mind that "the world's most valuable resource is no longer oil but data" [55], there is a need to reassert who is empowered through the usage of digital infrastructures. If proper legal frameworks are not in place, while the selling argument of digital infrastructures is to empower people, the huge amount of information collected through them seems to empower a handful of already powerful digital monopolies or Internet giants. Another scenario requiring assessment relates to the opportunities that they offer to groups representing unheard voices in the society. While such groups use digital infrastructures to openly share their political opinions at a low cost and without censorship, many governments have responded by demonizing and attacking them [56]. Given the research gap in impact assessment of digital infrastructure usage, efforts should focus on investigating frameworks for their transparent usage, how power is delegated through such infrastructures, legal aspects for ensuring user's protection, as well as on building human capacity for raising awareness about the consequences of their usage.

Proposition A3. Policy makers are losing the race to develop and enact laws that protect citizen rights while global companies are taking advantages of new business models enabled by digital infrastructures (Government weaknesses and oligopolists digital power).

Summary: The underestimated amount of user behavioural data collected by digital infrastructures has become the most powerful tool for targeted marketing. Powerful private companies are investing considerable efforts in designing services for users to spend as much time and resources (including personal data) as possible within their owned platforms. At the same time, governments are late to react in regulating such practices, leaving citizens unprotected.

Comment: Internet giants have powerful resources to collect and process user's personal information gathered through their owned digital platforms. They process information in the "context of prediction algorithms, an omniscient, opaque machinery that threatens to erode the very foundation of privacy". In addition, they have the ability to dictate user's attention by determining which content is shown to them [57]. For example, Luca et al. [58] demonstrate that Google increasingly develops and promotes its own content and that the mechanism they use to show search results "would lower the chances of consumers finding the products they need by one-third". Internet giants, like Google, Amazon, and Facebook, are "benefiting from the network effects whereby the popularity of a service attracts more users and thus becomes self-perpetuating". Thus, a main risk is the likelihood that they benefit from the commons by capturing the value derived from their information, and while doing it, they are precluding others from doing the same [59]. Filippi and Vieira explain that "the content holder has become as powerful as, if not more powerful than, the copyright owner" [59]. Given the facts, digital infrastructures, governed by few oligopolists, are creating a kind of "digital curtain" between our presence in the digital (virtual) world and the real (physical) world. In such scenario, governments become a kind of administrator of large trade of (social) values and products. This is particularly relevant in Latin America given that $78.4 \%$ of Internet users participate in social media (compared to $63.6 \%$ global average) [60], local industry and SMEs are usually not resourceful and do lack capacity to compete, and governments are losing the race to enact laws that protect civil and SME rights in front of Internet giant practices.

Appendix A.2. Propositions on Artificial Intelligence: Social Impacts of Algorithmic-Based Recommendations: Carlos Chesñevar

Proposition A4. Ubiquity of Agreement Technologies in Digital Society will have a deep impact in human-based decision making (Adaptation to integrated agreement technologies). 
Summary: AI-based tools and technologies will become ubiquitous in sustainable digital environments; rather than operating on a "stand-alone mode", such tools will have to negotiate and carry out agreements. Citizens should become increasingly aware (and educated) of the rationales underlying mechanisms for decision making using these technologies.

Comment: Agreement technologies (AT) [61,62] refer to computer systems in which autonomous software agents negotiate with one another (typically on behalf of humans) in order to come to mutually acceptable agreements. An agent may choose whether to fulfil an agreement or not, and it should fulfil it when there is an obligation to do so derived from the standing agreements. Autonomy, interaction, mobility and openness are key concepts studied within the AT approach. In the last decade, AI-based tools of different kinds have evolved to become ubiquitous to provide "agreement metaphors" for different aspects of everyday life. Thus, provided the proper context is given, a user searching for "Mars" in a browser when looking for candies should get different results from an astronomer searching for the same term. Similarly, searching for a restaurant on the mobile phone in a particular city provides different results according to the user's location. It is expected that the combination of different user features (providing suitable "contexts") will lead to expanded capabilities in AI-based tools. Some recent aspects where these elements have been analyzed include modelling social empowerment via social networks (e.g., as in [63], where "agreement" in public opinion can be abstracted away as a "cloud of statements" in a social network which correspond to different user contents have a similar sentiment towards a particular keyword). In this setting, a possible unseen is how citizens will perceive and adapt to enriched "agreements" or contracts (which will become more and more sophisticated as AI tools evolve. To give an example, current social networks "suggest" a person as a potential friend. The user "agrees" to give some degree of belief to such suggestions. In the future it is expected that more context-based information is involved, so that humans will probably delegate more complex "agreements" to AI tools.

Proposition A5. Explanation abilities expected from AI technologies will play a major role, resulting in a social demand for improved recommendation and explanation capabilities in future sustainable digital environments. (AI-tools \& recommendation capabilities).

Summary: One of the most requested AI-based services is connected with recommendations of different kinds in different online services (Amazon, Booking.com, Netflix, etc.). Current deployments use mostly quantitative metaphors (stars, rankings, etc.), which are not naturally connected with human-centric explanation abilities. New metaphors are expected to emerge.

Comment: Recommender systems [64] represent an important addition to different online platforms in our current digital society where the user is confronted with many choices. To come up with recommendations, recommender systems usually rely on user preferences, popularity indexes, or on similarity measures defined between users or contents, which are computed on the basis of methods coming from the social sciences, the information retrieval or the machine learning communities (see [64]). Although the effectiveness of these kind of recommenders is remarkable, there are significant limitations $[63,65]$. On the one hand, these quantitative models are not equipped with mechanism to revise previous conclusions; thus, given that the dynamic nature of user preferences usually leads to conflictive and incomplete domain information, these recommenders deal poorly with changes in preferences. On the other hand, these quantitative approaches do not have a clean underlying model that is easily understandable by the user (thus providing "brittle" explanations to support recommendations). As mentioned in $[63,65]$, qualitative explanations are relevant because users prefer recommendations when they can understand the reasons behind its selection. We contend that one of the "unseens" related to the growing popularity of recommendation services is associated with the lack of human-centric explanation abilities (involving e.g., qualitative issues that should go beyond providing a bunch of reviews written by other human beings. In future digital environments, there will be an increasing need and demand of enriched explanation capabilities supporting AI-tools. 
In this setting, evolving argumentation technologies $[63,65]$ might play a meaningful role in providing rationally justified decision processes. Trust, manipulation, provenance, and reputation are also relevant issues, including the question whether a recommendation from an individual or a program might receive more (behavioral) acceptance, as well as the impact of such recommendations in education, culture, wealth, and poverty issues in South America.

Proposition A6. Increasing role of AI tools in sustainable digital environments will require redefining ethical issues and social contracts with an impact on cognitive smart cities. (Ethics for AI and smart cities).

Summary: The evolution of the Internet of Things (IoT) will contribute to provide new sources for building a "digital public opinion" of anything (cars, people, organizations, etc.). This digital image will clash eventually with the needs and requirements of cognitive smart cities, involving new ethical issues related to AI technologies.

Comment: As pointed out in [66], the development of smart cities and their fast-paced deployment is resulting in the generation of large quantities of data at unprecedented rate. This calls for a new generation of approaches to cope with the phenomenon of "wasting unlabeled data" [66]. As pointed out in [66], even though there have been several discussions on the management of big data in the context of smart cities, there is still no clear answer on how to use the enormous amounts of collected data. At the same time, different stakeholders in society (organizations, politicians, citizens in general, etc.) will be more and more recognizable in terms of a "digital image", generated from data coming different sources. Social networks, for example, can help provide data for performing consumer insight mining [67]. Cognitive smart cities [66] refer to the convergence of the emerging Internet of Things (IoT) and smart city technologies, their generated big data and AI techniques. In this context, a possible "unseen" is the clash between the "digital image" of different stakeholders in society and needs and requirements in cognitive smart cities, resulting in new ethical dilemmas. Ethical dilemmas refer to situations in which any available choice leads to infringing some accepted ethical principle and yet a decision has to be made $[68,69]$. As pointed out in $[69,70]$, the AI research community realizes that machine ethics is a determining factor to the extent autonomous systems are permitted to interact with humans. These ethical dilemmas will have an even bigger impact when considered in the context of collective ethical decision-making, which might include the redefinition of traditional social contracts in society. Argumentation-based explainable AI (see, e.g., [65]) can be a good approach suited to the consequentialist ethics, commonly adopted approach for implementing AI ethics.

\section{Appendix A.3. Propositions on the Dark Side of ICT: Luiz Antonio Joia}

Proposition A7. Developing countries are implementing ICT trying to pursue the concept of "development" as understood and applied in developed countries. Yet, this will not fulfill their actual needs and solve their developmental challenges. (ICT in developing countries).

Comment: Some time ago, a debate arose regarding whether or not the developing countries should invest their scarce monetary resources in Information and Communication Technology (ICT) [71]. In other words, is it relevant and does it make sense for developing countries to develop its own ICT projects when faced with such vast and pressing socio-economic dilemmas and challenges? This debate is now considered unfounded, as it has since then been verified that ICT implementation is of paramount importance for developing countries [72]. Thus, the crux of the matter is not whether ICT initiatives must be undertaken in developing countries, but rather which ICT endeavors should be chosen to contribute to the country's development. The ICT potential for the development of developing countries is no longer in doubt, as several scholars have expounded on the developmental impacts accrued from ICT [73-78]. However, it is also true that ICT projects in developing countries striving for the development of the region are far from being a universal success, as several have fallen short of their intended outcomes [71]. Therefore, the key issue on that is what does "development" 
mean for developing countries $[79,80]$ ? That is to say, does the word "development" have the same meaning for developing and developed countries in the world [80]? Or, are ICT endeavors just reinforcing socio-economic gaps that are already found in the developing countries [81]?

Proposition A8. The heavy use of social media is fostering popular demonstrations worldwide, which will lead to an increasing distrust with political constituted leaderships and by consequence growing crises of representation. (Social media and popular movements).

Comment: Democracy is one of the factors that favor the emergence of popular demonstrations [82]. One can also cite the economic condition and a demanding agenda, as other conditions capable of triggering social movements [83]. According to Lugão et al. [84], in Europe, for example, several countries have hosted popular protests against the austerity policies adopted since 2012, as a result of the international economic crisis of 2008. In Brazil, as pointed out by Ramos and Oliveira [85] and Joia [86], the events of 2013 were sparked off by the yearning of the population for a political agenda that met their expectations and needs. In addition to that, for Castells [87], the digital networks represent the new social morphology of our societies, since the diffusion of network logic substantially modifies the operation and results of production processes, experience, power and culture. In this way, the Internet is more than a means of communication or a working tool; it is also an essential means of interaction and organization for contemporary networked society [88]. Based on that, Shirky [89] stresses that demonstrations with summons for physical presence are organized by mobilization on social media and, from that point onwards, demonstrate their strength with the massive presence of people on the street, united around a call for change. Castells [83] and Papic and Noonan [90] also explain that social media-enabled popular demonstrations have neither leaders nor hierarchy, mimicking the horizontality of the network, thereby reflecting distrust with constituted leaderships and leading to growing crises of representation. These characteristics are intentional and have strategic significance, since organizations gains strength against possible oppression via distributed networks, since there is no central point of control that can be repressed or controlled.

Proposition A9. The heavy use of smartphones has generated both positive and negative consequences for their users, thereby developing paradoxes that lead to the emergence of tensions and anxieties that are sources of paralysis for the users. (Tensions, anxieties, and the heavy use of smartphones).

Comment: The increasing penetration of smartphones around the world shows the importance of the technology and the concept of being connected as a way of implementing the idea of belonging to contemporary humankind. Thus, this new order represented by the growing importance of access to information and the possibility of being permanently connected is significantly changing the social dynamics, permitting new forms of collaboration and interaction [91-93]. Yet, studies about technological paradoxes have claimed that information and communication technology (ICT) adoption has generated both positive and negative consequences associated with its use by people, who are most of the time unaware of them [94,95]. According to Barjis et al. [96], mobile wireless technologies, such as smartphones, have redefined the social dynamics via new modus-operandi. Thus, at the same time as smartphones are used in the daily lives of individuals, contributing to more agile communications, they can also provoke addiction, anxiety, and encroachment on the free time of these individuals [94,95]. In sum, the ambiguities and paradoxes arising from the heavy use of smartphones generate internal conflicts in users that need to be administrated by them [97]. Thus, it is important for people to be aware of the conflicting aspects associated with the heavy use of smartphones, in order to develop coping strategies that can range from neglecting ambiguities, accepting them, or challenging and defying them $[98,99]$. 
Appendix A.4. Propositions on the Rebounds of Smart Cities: Maria Alexandra Cunha and João Porto de Albuquerque

The stage of development in smart cities in South America: Although 'smart city' is a research term used in several fields of knowledge, a lack of consensus remains regarding the theme [100]. The term 'smart' is associated with the development of solutions to urban problems using technology. The 'smart' wave succeeds the term e-government, which is older and, perhaps for this reason, more widely studied, and is linked to the modernization of the public sector with the use of information and communication technology (ICT) to improve the efficiency of the operational and administrative processes of governments [101]. It is also associated with the use of the internet in the public sector to provide online services and to expand democratic practices [102]. Both e-government and smart city initiatives rely on technology infrastructure, hardware, software, networks, the internet, services and applications, and the use that local governments make of them. In Latin America, e-government projects have been in place since the late 1990s. Since then, and despite the efforts of governments, ICT usage and management in Latin American cities remains deficient. For example, the Brazilian context shows low use of technology in governmental processes. ICT infrastructure is poor, and great challenges have to be overcome when it comes to ICT governance and management [103]. Besides the inequality among local governments, it is important to note the lack of skilled staff to manage IT in smaller local governments and/or more remote regions.

Proposition A10. There are wide disparities in the competencies of IT Governance in Latin American cities. IT governance models are required that consider these uneven capabilities of cities and their development. There is a risk of technological lock-in on a city-wide scale (IT Governance).

Comment: Smart city initiatives rely on technology infrastructure, e.g., hardware, software, networks, the internet, services and applications. In Latin America, e-government projects have been in place since the late 1990s. Since then, and despite the efforts of governments, ICT usage and management in Latin American cities remains deficient. For example, the Brazilian context shows low use of technology in governmental processes. ICT infrastructure is poor, and great challenges have to be overcome when it comes to ICT governance and management [103]. Besides the inequality among local governments, it is important to note the lack of skilled staff to manage IT in smaller local governments and/or more remote regions. IT governance models are required that consider this gap in the skills of staff. Associated with IT resource management, IT governance models should consider developing IT skills in short and successive cycles. E-government public policies recommending generic principles in Latin America, imported from cities of the global North, may not have achieved the expected effects, and this may also occur in the case of smart city initiatives [104]. The research of e-government and smart cities in developing countries should consider the steps that must be taken at the municipal level, especially those steps that should be taken to acquire IT management capabilities. The challenges are not trivial and actions that consider differences among cities can leverage results. Regarding an "unseen" effect, this context of a lack of IT management capabilities could mean the risk of technological lock-in on a city-wide scale. The asymmetry of information between public administrators responsible for IT in the city level and local and/or global technology providers could lead cities in Latin America and other regions around the globe to become hostages of technology platforms in long-term contracts. The maintenance costs for technological infrastructure are a common problem in cities around the world, but cities in Latin America have additional difficulties related to their lack of skilled staff and consequent dependence on IT companies. This means that cities would become dependent on technology and services that they are not capable of maintaining, let alone of further developing to suit their evolving needs. 
Proposition A11. Latin American cities are characterized by spatial inequalities. More developed regions are surrounded by areas of poverty and vulnerability. Smart city initiatives that disregard these inequalities may accentuate them. (Spatial inequalities).

Comment: Researchers who investigate the spatial implications of smart city initiatives have pointed out the risk of gentrification [105]. Gentrification was a localized phenomenon in some suburbs of big cities in the 1960s [106] but is now taking place in cities of all sizes in all regions of the globe [107]. Using digital technology to improve neighbourhoods in Latin American cities, may cause gentrification in these areas, for instance due to higher real estate prices, that will make them inaccessible for impoverished citizens. Large cities in Latin America are generally made up of a central region that is often an important municipality, sometimes even a state or national capital, surrounded by neighborhoods and/or municipalities subject to poverty and a number of vulnerabilities and deprivations. In addition to "pushing" people to poorer regions, smart city initiatives may also be pushing problems to these same regions. As a result, spatial inequalities will be accentuated. There will be islands with better social indicators and, at the same time, peripheral regions with worsening development indicators. Measuring the impact of smart city initiatives must go beyond the frontiers of target neighbourhoods and cities, which are often wealthier than the surrounding areas. In Latin America, with a large part of the population living in urban agglomerations, indicators must be developed that measure the impact of these initiatives considering spatial inequalities. If these inequalities are disregarded, the positive impacts of smart cities initiatives can be overestimated by only measuring wealthier regions, leaving "unseen" the effects in surrounding deprived areas. This can cause an "ecological fallacy" in which average indicators are improved, but the poorer population have to struggle with greater inequality.

Proposition A12. In smart cities, technologies for digital participation have an ambiguous character between empowerment and instrumentality. The way citizens are engaged in the process of data production is as important as the data generated itself (instrumental digital participation).

The dissemination of digital technologies has generated a sustained interest in initiatives that seek to involve citizens and communities in the generation of data. The potential for democratisation and empowerment of eParticipation and citizen-generated data has not only been acknowledged by grassroots advocacy and activist groups but is also increasingly promoted by a wide-range of mainstream actors such as humanitarian organisations [108] and the United Nations Programme for Human Settlements [109]. Smart city initiatives have also emphasised the role of digital participation [110] and in fact, a recent report by McKinsey Global Institute proposes that smart cities are entering a "new phase" of citizen-centric initiatives [111]. However, alongside this acknowledgement of the potential for citizen data production, there is a growing body of literature that offers more critical perspectives. For instance, they point out structural barriers in the society that may prevent some social groups of producing or interpreting big data [112]. This could create a 'delusion of democratisation' [113] by increasing participation only within a relatively homogeneous group of citizens, which is unable to effectively overcome marginalisation issues [114]. Furthermore, the designed technologies may follow externally defined "programmes of participation" [115], enabling pre-defined practices of data production which do not necessarily allow contestation or empowerment [116]. As argued by Albuquerque and Almeida [108] the contradictory views on citizen data production are due to a constitutive ambivalence of "citizen sensing": it can mean that citizens will develop enlarged capabilities of perceiving phenomena and articulating alternative worldviews (and thus empowerment); or alternatively, citizen's capabilities can be reduced to equate a sensorial device to capture (mostly pre-defined) environmental signals (thus implying instrumentality). Should this constitutive tension be left "unseen" in purportedly "citizen-centric" smart city initiatives, even if citizens are given the opportunity to produce data (and thus "speak"), they could be doing so by only following the possibilities foreseen in the digital technologies, which could be resting on a set of non-problematised (and potentially problematic) ontological assumptions and interests. Real citizen empowerment can 
only be achieved in the participative production of data by giving attention to the form and process with which the relationship between the public sector and citizens are established, i.e., to the modes of engagement between citizens, government, and digital technologies.

\section{Appendix A.5. Propositions on Economic Change: Carlos O. Quandt, Alex Antonio Ferraresi and Eduardo Damião da Silva}

Proposition A13. Digital readiness of the labor force (ability to adapt to digital work).

Comment: The global trend of automation of manual work and some types of analytic work affects the economic system and institutions. The concept of "digital readiness" applies not only to industries, but to the labor force as well. Even though access to information has become almost universal, the supply of professional education and labor qualification in the region has not been restructured to provide effective qualifications so that workers are prepared for the impacts of the digital transition in the labor market. Changes are much faster than the ability of regional governments to regulate labor practices and to offer training to the labor force; unemployment in the region is already high, and overall skill levels are low. Frey and Osborne [117] estimate that almost half of all the new jobs require high skills. Digitization is likely to contribute to labor market polarization, assuming that low- and middle-skill jobs are more susceptible to automation. The repatriation of activities previously outsourced to low-income countries by the most developed countries is also likely to occur [118]. The uncertainties and challenges for local economies to adapt is high. Education and training are still geared toward traditional professional roles. This is not limited to well-defined areas such as computer science or engineering, but also to the need for the development of trans-disciplinary capabilities. These transcend formally accredited academic disciplines and agencies, and include other kinds of tacit, non-specialist knowledge from practitioners and local communities, as well as non-linear thinking, creativity, entrepreneurship, communication and problem-solving skills, all of which are harder to automate. The effects may be delayed in the region if investment takes longer than expected to be shifted to the development of the required technology, to change organizational processes and practices, and consequently to promote its diffusion in the regional economic system.

Proposition A14. Digitalization labor divide.

Comment: The rise of the knowledge economy and intangible assets as the basis for economic growth. As knowledge is increasingly seen as a strategic resource, the impacts on regional productivity and profitability tend to be high, considering the importance of labor-intensive, resource-intensive and commodity-based economic activities in the region. As automation might replace completely the bundle of tasks constituting a job, productivity will increase, but the expropriation from specific skills poses new challenges for education systems and support institutions in terms of specialization and retraining. The increasing interactions between workers and cyber-physical systems imply a complementarity in human-machine relations, but the roles of each may vary widely. In one scenario, smart machines would not be more than tools that support human decision-making, which ensure a dominant role for highly qualified workers over machines. In such cases, the demand for knowledge workers will affect national and regional strategies for human resources and economic specialization, given the need for new competences and higher qualifications. It is clear that market frictions between supply and demand for high-skilled employees are already occurring in more developed countries, particularly in the ICT sector [119]. Also, as traditional manufacturing loses its importance in the process of economic development, less-developed regions will be unable to follow that path. Rodrik [120] argues that "countries are running out of industrialization opportunities sooner and at much lower levels of income compared to the experience of early industrializers." While the prospects for productivity growth are enhanced, increasing inequality should be a concern. 
Proposition A15. Big Data and digital property rights.

Comment: The dematerialization of wealth production associated with technologies such as IoT, big data and cloud computing raises questions about intellectual property rights, in addition to privacy, security, and ethical concerns. For example, the Big Data Research and Development Initiative that has been implemented in the US since 2012 suggests that new policy solutions may be necessary to protect privacy, to clarify data ownership, and to secure data in the highly distributed networks that are becoming increasingly common in big data application scenarios. Considering the important role of public sector institutions in generating research and technological development, the ownership of intangible/dematerialized resources is still undetermined, and consequently the appropriation of their economic value. For instance, the digital transition and big data are spurring demand for data specialists and skills for data analysis that exceeds both the current supply and the current capacity of the education and training systems. Big data also brings new security concerns related to the ability of government institutions to address cybersecurity problems, as well as corruption, which could lead to big data breaches and the potential misuse of data. As individual interactions with all kinds of public and private organizations are increasingly subjected to large scale surveillance, privacy has become a merchandise, and the undesired effects of big data tend to be unequally distributed. As Jerome [121] points out, discrimination, profiling, tracking and exclusion "threaten the self-determination and personal autonomy of the poor more than any other class."

Proposition A16. Digital readiness.

Comment: The concept of "digital readiness" applies not only to industries, but to the labor force as well. Even though access to information has become almost universal, the supply of professional education and labor qualification in the region has not been restructured to provide effective qualifications so that workers are prepared for the impacts of the digital transition in the labor market. This is not limited to well-defined areas such as computer science or engineering, but also to the need for the development of transdisciplinary capabilities.

Proposition A17. Digitally disrupted economies.

Comment: The "sharing economy" and "platform economy" associated with cyber-physical systems and mobile technologies disrupt traditional manufacturing and services in a growing number of sectors. This creates opportunities for new business models and wealth creation but raises concerns about regulatory issues and the creation of monopolies/oligopolies. Another unanticipated side effect could be further inequality in the labor market: the power balance has shifted in favor of workers with digital skills, especially when they are employed in sectors where digital skills are in high demand, while a significant part of workers will be stuck with low capabilities and low value-added "gigs". As Katz [122] points out, "once the infrastructure gap has been addressed, human capital becomes the stumbling block". It should also be noted that the on-demand economy is not a main source of income for most people, and this type of work is often underreported on labor surveys. Currently, on-demand platforms do not provide sufficient work to generate income similar to that earned in traditional jobs. However, if it continues to grow at the current pace, it will ultimately fundamentally change the overall economy, not only sub-segments as it does today [123]. The fragile welfare institutions in the region will be hard pressed to respond to the shift in the balance of power between employers and gig workers, under increasingly virtual working relationships. Although discussions in this domain tend to focus on work conditions and remuneration, the actors in the on-demand economy typically lack representation or self-organization, and collective bargaining is largely absent. Since they are not formally employed, they also lack social benefits such as minimum wages, sickness and holiday pay, retirement benefits, and access to training opportunities. The potential dismantlement of the current employment model also implies undesired effects on the political system. Employment benefits, 
healthcare, and social welfare systems rely mostly on salary-based taxes that account for a substantial share of public resources and budgetary sustainability [124].

Proposition A18. Changing the agricultural supply chain. (Digital agriculture).

Comment: The growing insertion of new technologies in the agricultural value chain open new opportunities for increased rural productivity but raises concerns about the reduced role of local farmers in the supply chain, as well as with genetic diversity and sustainability of small farms. This has been addressed in the region for some years (as in the case of transgenic crops, and specially "Monsanto's Roundup Ready" case), but policies to mitigate the unintended side effects are still unclear. New technologies are also related to the labor force shift that is already affecting emerging economies through the "premature deindustrialization" effect [120]. Even at the lower wage levels that prevail in the sector, increased insertion of new technologies in agricultural production chains is becoming cost-effective and capital-labor substitution is going to occur not only in manufacturing, but also in agriculture.

Appendix A.6. Propositions on Industrial Change: Pablo Collazzo-Yelpo

Proposition A19. Digital Competitiveness: meaning and performance across South American economies (digital competitiveness).

Comment: Readiness to exploit digital transformations begs for a coalition of 'doers' and 'shapers', as South American firms (the 'doers') need to build up digital capabilities to increase competitiveness, while policy makers (the 'shapers') should upgrade the overall context that enables the development of digital technologies -an open, agile regulatory and technological framework.

Proposition A20. Industry 4.0 and the need to reconcile the digital world with the physical world-The South American case (Industry 4.0 divide).

Comment: Advanced production techniques leveraging smart technologies create the enterprise, interconnected, data-driven, yet one that should plug back in the physical world to deliver more efficient decision-making and higher productivity. Industry 4.0 is beyond manufacturing, as digital technologies are transforming not just production, but organizations altogether. It is not whether robotics, analytics or the Internet of Things are to redesign operations but how to go about, at firm level, selecting the digital tools that allow people to be more efficient and enhance output value. Digital transitioning should arguably be firm-specific, as companies combine different resources, start off the journey from different points of departure and seek a unique competitive advantage out of developing digital capabilities. The single most important change that Industry 4.0 is likely to unleash is real-time access to data, allowing information to spread faster, albeit not always accurately, and prompting firms to be sharper, more responsive and flexible in their decision-making process. However, South America is far from a level playing field - rather a land of asymmetries. And the gap between the digital-ready and the digital-lagger is remarkable. As the divide is likely to lead to a zero-sum game, for the benefit of the former at the expense of the latter, the question remains whether the typically bigger, more resourceful firms may have an incentive to perpetuate their digital advantage-for instance attempting to reduce knowledge and technology spill-overs across supply chains. Additionally, market imperfections may prevent laggers from catching up, a systemic liability addressed in the following Proposition (21).

Proposition A21. Firms across regions operate in diverse business environments, and South America offers a bittersweet mix of enablers and barriers as companies transition to a digital environment. 
Comment: The expected productivity gains resulting from digital transformation require a steady upgrade of the business environment across the region -increased firm-level productivity is contingent on a better Diamond, in the sense of Porter [125]. In order for Industry 4.0 to fully unlock the productivity gains resulting from an increasingly digitalized marketplace, the business environment in which firms compete in the region arguably needs significant upgrades. Location plays a central role in shaping firm-level productivity, and the diverse, asymmetric context in which firms operate across South America, results in remarkably uneven starting points in the regional digital race, in very different national and industry Diamonds [125]. The underlying rationale of the Diamond model (ibid.) lies in the claim that natural endowments are unlikely to explain a region's competitive advantage, but it is rather the local capacity to innovate and upgrade its business environment and as a result unleash firm-level productivity what accounts for its relative competitiveness. And when it comes to digital competitiveness, a potential unseen would lie in the widening gap likely to be experienced by firms across different Diamonds in the region, with a very different set of factor conditions -notably education and digital infrastructure-, as well as equally dissimilar regulatory frameworks, which typically set the pace of digital transformation.

Appendix A.7. Propositions on Big Data in Occupational Health: Frida Marina Fischer, João Silvestre Silva-Junior, Maria Carmen Martinez, Rodolfo Andrade de Gouveia Vilela, Luis Fabiano de Assis, Maria Regina Alves Cardoso

Information about OSWH: The Digital Observatory on Health and Safety at Work (OHSW) (http://observatoriosst.mpt.mp.br) is a tool for knowledge management and the promotion of Decent Work, aimed at informing citizens, workers, employers and public an overview of the occurrence of occupational diseases and accidents in Brazil. It is the largest, most affordable, and most detailed big data containing consolidated information on the subject in the country. Thus, it is an important mechanism to subsidize the development, monitoring, and evaluation of public policies at the national, state, regional and municipal levels. The observatory facilitates access to data that previously was scattered in government databases or general yearbooks (from the Ministry of Planning, Development and Management, Ministry of Labour, Social Security Secretary), which made it difficult to research the subject and its understanding. The tool is maintained by the SMARTLAB for Decent Work (https://smartlab.mpt.mp.br). The observatory was built in accordance with the best international practices for the promotion of public policies, highlighting three main axes: 1 . Promotion of transparency and accountability through the organization and availability of data and information of public interest for public access in general, with progressive adherence to the open data standard; 2 . Development and availability of tools for diagnosis, planning, management, monitoring, and evaluation for different social actors involved in promoting decent work, based on results-oriented management principles; 3. Expansion of the knowledge on issues related to the world of work-considering its intersection with the human rights agenda [126]. There are approximately five million companies in Brazil that contribute to the social security system. This number corresponds to around 54 million formal jobs [127]. Based on the information provided by the OHSW, between 2012 and mid-2018 there were, on average, per year: 653,000 work injuries, 2400 work fatalities; 51,300,000 lost workdays; approximately 1.1 billion US\$ of expenses due to social security benefits.

Proposition A22. Disclosure of work-related diseases and work injuries.

Comment: Public access to data on the notification of work-related diseases and work injuries as well as social security benefits can support the discussion of priority actions to improve safety and health at work. The OHSW already provides number of injuries' notifications, social security expenditures, lost workdays, fatal injuries, geographic location, branches of activity, and profile of the workers. New data will be gradually made available, such as: even more detailed econometric estimates of the impact of work injuries and work-related diseases on the economy, on productive activity, and on human development; incidence rates, mortality and lethality by specific causes, as well as economic activity and 
demographic data among others. There is a possibility in the future of downloading microdata of interest to users, ensuring, as provided by national legislation, the safeguarding of confidential data of individuals. As a consequence, there may be a change in the management of public and private enterprises in order to improve health promotion programs and prevention of work-related diseases/injuries. On the other hand, the potential increase in the inspection and the economic impact of the increase in the rate of insurance of work-related diseases/injuries may encourage the underreporting of events. By not having reliable estimates of work-related illnesses and work injuries, attention is focused only on some job clusters ignoring others that may also pose risks to workers' health. This might lead to the maintenance of current high numbers of negative health outcomes, including work injuries, or even to worsen working conditions.

\section{Proposition A23. Digital data analytics and early functional aging.}

Comment: Information on work-related injuries at the national level that negatively impact workers' ability can contribute objectively to the prevention of exclusion of workers associated with early functional aging. However, underreporting of events can affect estimates of early functional aging not favouring epidemiological surveillance of workplace risk factors. Additionally, data from the Ministry of Health could provide detailed information on life-course exposure. The conditions and organization of work are variables that influence the health status and work ability [128]. Therefore, information on work conditions can help directing actions to promote and protect workers' health. The identification of stressors at work helps to adopt general and specific measures, which aim at the prevention of injuries and work-related diseases. One of the positive effects is the maintenance of work ability and the consequent extension of productive working life. Keeping people at work with greater experience, who are generally older, can favour the adoption of beneficial strategies and productive processes, given the greater ability of those workers to solve complex problems, to take appropriate decisions, to convey effective communication and leadership skills [129]. However, unintended side effects could be: (a) Keeping workers on the job for a longer number of years may reduce opportunities for young workers to enter the workforce; (b) Job discrimination on employment decisions, selective private health insurance policies such as fixing individual fees according to health status or even rejection of health coverage. A recent labour reform [130] allows temporary and/or intermittent hiring and may favour the offer of poor jobs, with limited social benefits.

Proposition A24. Payment of social security benefits and public policies.

Comment: Data on the amount of expenses with payments of social security benefits due to work disability (work-related injuries/diseases) contribute to the discussion on the balance of the public accounts of the Brazilian social security system. The diagnosis of the deficit between the financial contributions to the system and the expenses corroborates understanding future social security changes. This aims to achieve a balance between the costs and the incoming revenues. In Brazil, there is already a draft of a constitutional amendment that proposes the reduction of workers' access to social rights provided by the current social security system [131]. Information on the economic burdens of work-related injuries/diseases can also be used to subsidize changes in the employer's tax system, taking into account the health and safety risks for workers, with negative impacts on workability. Such changes in legislation can promote social exclusion through an increase in the rigor of health assessments for work admission as well as reduction of protection provided by the social security system in cases of work disability due to work injuries/diseases. Financial trends, political and ideologies are important aspects challenging the misuse of information by inappropriate recording and/or manipulation of data and events by underreporting or falsifying or poor quality of information or by typos, data programming or analytical errors. In order to achieve a better integration of big data analytics the Brazilian federal government is implementing a new system that digitally integrates labor, social security, and tax information compulsorily filed by all employers (eSocial) [132]. 
Appendix A.8. Propositions on Digital Democracy: Diego Cardona and Aurora Sánchez

\section{Proposition A25. The Myth of Connectivity.}

Comment: Although connectivity as a government policy to promote the digital society has been a hope for governments in Latin America, the reality is that, despite the significant investments made, the impact has not been as expected. Connectivity understood as access to effective and efficient communication systems, in particular to the Internet given the access to the information as a source of power, evolves faster than the investment capacity to update the technological equipment required and in those terms can be wrongly concluded the impossibility to maintain the community at the desired digital society, however it is important to understand that what is important for communities, rather than access to information, is to make intelligent use of it to provide efficient services. An interesting example of this type of approach is the MuNet project, led by the Organization of American States in various Latin American countries. Among others, the Patzun case at Guatemala presents a "best practice" balancing needs and available resources, which also takes into account not only technological factors, such as connectivity or access devices, but also social, cultural, and political factors that may become more important for the success of any e-government initiative. As a result, appropriate connectivity should increase the visibility of public matters, the trust in public administration and improve the public administration control. Furthermore, connectivity should facilitate citizen access to public information, procedures and services and obtain the citizens' feedback in the decisions making process, working in order to obtain effectiveness and efficiency at the offered services to optimize the governmental investment in ICT. As a conclusion, the interest of governments should be providing connectivity with appropriate technology to meet emerging needs instead providing it with the latest technology $[133,134]$.

Proposition A26. Redefining truth in democracy: Partial and post truth may influence positively or negatively democratic processes.

Comment: The World Wide Web has created local and global awareness allowing citizens to receive information about their local community, state, country and the whole world. In this context, social media is a key platform that has redefined the role of citizens from simple consumers of media to content producers and users simultaneously. This digital revolution has provoked important changes in what is known as a democracy not only influencing the way people interact with each other and with their communities but also offering a unique opportunity to pursue their goals. Now, new communities have emerged with a more comprehensive perception of the world and with the power to mobilize people to pursue changes that could benefit the whole society. The impact of this digital transformation on democracy could be enormous in areas like the development of democratic processes and information security. Platforms like twitter or Facebook may inadvertently turn elections, change decisions like Brexit or change power structures, and the processes of gathering, producing, and disseminating news may produce fake news, junk science, computational propaganda or aggressive micro-targeting. The changes that digital media is introducing are not merely Twitter or Facebook 'revolutions', like the Arab Spring or "los indignados" in Spain, but rather real changes in socio-technical configurations and cultural contexts that may affect the truth and trust in democratic societies [135]. Therefore, the challenge is moving the attention from the performance of those systems to the development of a new democratic system that need to deal with populism, political polarization, far-right extremism, radicalization, waves of hate against women and minorities, post-truth world, fake democracy and ultimately, the death of democracy [45].

Proposition A27. Ambiguities with social media, global awareness and local actions. 
Comment: Social media is increasing global awareness and generating local actions in real time on issues that may affect various communities around the world. This technology has become critical to promote social attention and engagement in social and political activities. The level of awareness about a social or political issue may be associated with the use of internet and social media as it was recognized by Huang and Hong [136] in the case of Asia. This phenomenon is generating what we can call a new type of civic activism where any user may impulse a social movement anytime from anywhere and if the movement represents a community it will reach people's attention. There are many examples of social movements using social media, and they have grown exponentially through the internet. Jost, Barberá, Bonneau, Langer, Metzger, Nagler, Sterling, and Tucker [137] analyzed the latest social movement, as the \#metoo, finding that social media platforms were crucial to exchange information, coordinate activities, and exchange emotional information in support or opposition to protest activities. Then, the evolution of communities from being traditionally physical to exist in the digital world, with no ties to a particular location, is generating a new type of political engagement which may impulse changes that were not planned. These new forms of civic activism may jeopardize traditional structures and the whole social system. For example, in Chile, during 2018, most universities saw a strike for women rights, and this movement is changing the whole power structure of those universities. Then, the danger of installing global issues with pressing attention through digital platforms is the lack of understanding about the needs, priorities, and level of preparedness of local communities and the interplay between the needs of local and digital communities.

Proposition A28. Reduction of information asymmetry.

Comment: Digital technology is enabling knowledge sharing at a fast pace reducing information asymmetry among individuals, communities, countries, and society. This technology that allows people to know the development of the whole world is creating higher expectations in all actors in society and generating a big gap between what it is known and wanted by people and the structures, actions, and services that those countries, communities, and governments can provide. The reduction of information asymmetry is happening in many spheres of society and is distorting the equilibrium of many systems in it. The access to information that was previously unavailable or denied to people allows them to become more efficient and make better and informed decisions. However, the acquisition of this knowledge could generate new demands, on both the government and companies, and the countries may not be structurally prepared to fulfill them. This pervasive effect can change the structure of society at all levels since and it is changing the way people think, interact, and act [138]. It is particularly interesting to see the changes in the financial systems, starting from crowdsourcing to the use of cryptocurrencies, the tourism sector with the online reviews and booking services, the education system moving increasingly online, and others. The consequences of this information asymmetry reduction may affect democracy as a whole when it is used by populist leaders to create chaos and take advantage of the situation, to generate commercial wars associated with the loss of privileges previously guaranteed or to keep the status quo [139]. This latter scenario may create protectionisms, destroy democratic systems, create inefficiency in the management of government resources, and redefine the way companies compete.

\section{Proposition A29. The Increasing Digital Inequality.}

Comment: The promise of the implementation of electronic government in its beginnings was the democratization of the benefits of the digital society increasing efficiency and transparency, however, in several cases it has been observed that despite efforts for integral improvements in connectivity, access to technological tools and digital training, the real effect in Latin America has been contrary to what was expected, instead of advancing towards the equity of the benefits of the digital society, it has actually generated an increasing inequality. Evaluations such as the Electronic Government Index of the United Nations or the Networked Readiness Index of the World Economic Forum show erratic behavior at the regional level. For example, in human capital, an inertial trend is observed, the presence at the Web of the 
Government seems to improve, however, the technological infrastructure does not allow for an effective reduction of the digital divide. On the other hand, the factors of public and macroeconomic policies for the use of ICT to improve the economic growth are conditioned by a turbulent environment that does not allow its optimal deployment. Likewise, the evidence on the impact of electronic government strategies on the corruption perception index of Transparency International or the GINI Index of the World Bank are not unanimous. While the region seems to have a positive behavior in the electronic government index and in the networked readiness index, no improvements are observed in the corruption perceptions index nor in the GINI Index. As a conclusion, despite a possible advance in the regulations and in the indexes of international evaluation of elements related to electronic government, its updating and improvement process is still under construction [140].

Appendix A.9. Propositions on Cybercrime: Rodrigo Sánchez Rios

It is known that the emergence of new technologies affected society in many ways, not only shortening distances and simplifying daily tasks, but also making peoples life busier and exposing them to more risks. Consequently, these advances made new forms of criminality possible, such as cybercrimes (an offense that specifically attacks software and hardware) and cyber-enabled crimes (a traditional offense committed with the help of the internet). As a response to this phenomenon, there are some propositions that deserve to be taken into consideration.

Proposition A30. What is considered crime offline must also be considered crime online.

Comment: First of all, besides the discussion of what is cybercrime, it is necessary to have in mind that the traditional offenses are still being committed, not in its usual form, but through the internet. And that, by itself, is already a challenge that must be faced by all members of the criminal justice system, regarding that the Law not always can predict every possible aspect of a crime. That being said, the Courts are having difficulty fitting these cyber-enabled crimes into the already existing legal dispositions. As an example, a fraud committed with the help of a social network must be punished in the same way as a fraud committed in person. Nevertheless, when we talk about a virtual environment, there are more obstacles from the prosecution point of view: the identity of the offender is not always easily found or even from where the offender is operating.

Proposition A31. The international cooperation is fundamental to fight cybercrimes and cyber-enabled crimes.

Comment: This proposition is highly linked to the latter, because those are new forms of criminality that do not occur in the classical way. These offenses are committed in a virtual environment and can cause as much damage as the traditional kind, but they cannot be as easily detected. That is why the cooperation between countries is so important in the investigation period and also in the actual prosecution phase, in order to collect evidence, enforce warrants, and even arrest people. The transnational nature of most of those crimes is one of the reasons that makes it so hard to fight and prevent them from happening. Countries have to cooperate with each other, especially through international agreements, so that all the information is obtained respecting both legal systems. In other words, the existence of a mutual legal assistance treaty in criminal matter is key to avoid discussions regarding the admissibility in court of the evidence obtained with the help of international cooperation.

Proposition A32. When the author commits a lesser included offense as means to commit another, both acts must be merged.

Comment: It is already known that the criminal justice system does not work easily with the new forms of criminality, mostly because there are aspects of those offenses that are not accessible to the public. Understanding cybercrimes and its circumstances require a specific knowledge that is not always available to the ones who work with the law (students, law enforcement agents, attorneys, 
prosecutors, judges, etc.). In this scenario, when there are two offenses and one is just a means to achieve the second, we must apply the "merger" doctrine, which indicates that the person can only be punished by the greater crime. That must also be observed in the cases involving cybercrime and traditional criminality, because the actions perpetrated in the virtual environment are now an important way to facilitate the activities of large criminal organizations, for example. Nowadays, several offenses demand this interaction between the online and offline world, such as: money laundering, human trafficking, terrorism, etc. Therefore, the problems that come with the use of internet for committing crimes must be analyzed through the perspective of only one conduct.

Appendix A.10. Propositions on Corruption: Edimara M. Luciano

Proposition A33. Outdated approach on processes analyses can increase segregated, fragmented, nonintegrated processes, data and technologies as well as bureaucracy.

Comment: ICTs have been increasingly used in anti-corruption initiatives [141]. Sometimes these efforts are more focused on technologies [142], instead of also focusing on organizational processes. Focusing the discussion straight on technologies can be good to convince partners, to answer to media pressures, and when it is difficult to deal with the pressure and influence of IT suppliers. Nevertheless, technologies, as modern as they can be, need to better support the organizational processes [143]. Frequently, processes analysis is put aside because it is not trendy and does not bring much recognition. Decision-making focused on technology more than on its suitability for the organizational processes (even considering that they need to be previously reviewed and changed) can increase the presence of segregated, fragmented, not integrated processes, data and technologies in governmental agencies. Consequently, it can increase short-term costs by selecting inadequate or unnecessary complex technologies, and long-term costs by increasing the number of ad-hoc solutions [144] and reducing the solutions lifespan. However, there is a risk of increasing bureaucracy in case the focus on processes retrogresses to the Business Process Reengineering (which in Brazil was also known as Organizations \& Methods instead of using a comprehensive and up-to-date processes approach connected with a better support to public policies and governmental strategies, and to citizens and civil servants necessities. It is crucial to develop state capacity on high-level discussion and decision-making related to organizational processes.

\section{Proposition A34. Initiatives focused on reducing bureaucracy can lead to under regulated situations.}

Comment: Initiatives related to the reduction of the levels of bureaucracy are vital to reduce the levels of corruption [145]. For example, bureaucracy hinders the establishing of companies [46]. This increases the vulnerabilities of public agents to corruption, more specifically bribery to speed up the process [146]. The ease of doing business ranking [147] is way to understand the level of bureaucracy in a country. When analyzing this ranking and the Corruption Perception Index [148] together, it is possible to observe that the least corrupted countries are also the least bureaucratic ones. The same occurs with countries at the bottom of both rankings: the more bureaucratic countries are also the more corrupt ones. The reduction of bureaucracy involves efforts to reduce the number of forms, documents, and steps citizens need to go through to use a governmental service, as well as the paperwork civil servants need to do to perform their duties. Debureaucratization frequently aims at lean administration [149]. In countries with high levels of state bureaucracy, laws, rules and procedures are complex, numerous and sometimes disconnected or overlapped, increasing the occurrence of over or under regulated situations [46]. Simultaneously, there are several initiatives focusing on increasing the number of digital services and trying to take part of the digital transformation. Despite the good intentions, it would be an unfortunate consequence if laws, rules, and procedures started to be changed without the necessary discussion and without considering all the inherent complexity, and focused only on giving fast answers to the civil society pressures. This situation can lead to under regulated 
situations, which can paradoxically increase corruption. It is necessary to develop state capacity on decision-making and governance focusing on long-term planning decisions.

Proposition A35. Anti-corruption practices can present rebound effects when they are not suitable to a specific context and are not chosen by proper collective decision processes supporting the governance process.

Comment: Corruption is often analysed as a legal, political or economic phenomenon. However, sometimes practices that are successful in some contexts are adopted through mimetic processes in contexts that do not share the same cultural or social beliefs. Considering that, the social-cultural-behavioral dimension needs to be observed in order to avoid the creation of anti-corruption practices that are not adequate in some contexts and, consequently, are difficult to legitimize and can generate rebound effects. The cultural rules show what is socially allowed, and whether something is accepted or penalized depends on culture, zeitgeist, sensitivities and social beliefs. The social approach considers that corruption is linked to the way a society tolerates both corruption and corrupt agents and is linked to social beliefs and socially accepted behaviors [150]. The attempt to understand whether cultural attributes can explain the variation in the level of corruption is the focus of the cultural approach [151]. The behavioral approach emphasizes the understanding that government practices are vulnerable to the practices of individuals acting in favor of the interest of private groups, transforming their behavior into corrupt behavior [152]. Corruption is a multidimensional issue and this fact requires that discussion and approval of anti-corruption laws, policies, rules, and procedures have to be done by proper collective decision processes supporting the governance process. Much attention has to be paid to how processes (e.g., public voting, multi-stakeholder forums, transdisciplinary processes) are carried out to avoid unrealistic populist solutions (e.g., an over complex system which may be easily undermined), which do not improve the current practices. It is critical to develop state capacity on transdisciplinary decision-making and governance focusing long-term changes.

\section{Proposition A36. Corruption reframes digital transformation.}

Comment: Progressively, efforts dealing with corruption are having better results when using the support of ICTs [153]. The opening data efforts on the increase of governmental transparency as a way to generate accountability are valuable initiatives to make society aware of corruption and also to allow social control. However, as important as it may be, it is not enough to deal with corruption. It is necessary a complex combination of technical, legal, social, organizational and behavioral measures, provided the same technology tools that are used to deal with corruption can be used to create new vulnerabilities. The decentralization of information leads to diminishing corruption opportunities [154], and digital transformation makes governmental policy systems smarter and more evidence-based. Digitalization increases the 'digital trail', which in turn could lead to a higher chance of getting caught in the act of performing corrupt practices [155]. ICTs increase the results monitoring and traceability of government employees' activities [156]. However, disclosed data, data from user digital trails or ICTs for monitoring can be used as a starting point for frauds or bribes. Corruption works as a net. If a node that was using cash payments as part of a corruption process is dismantled, something such a Bitcoin-based (i.e., alternative currency-based) Darknet can be quickly established and a new node is created. Ionescu [157] note that the majority of fraud and corruption is practiced through someone inside the organization. Consequently, when governmental services are digitalized, the corruption simply changes from an offline to an online practice. It calls attention to the necessity of more secure and automated systems, but also to the fact that corruption has been redefined by digital transformation because of the new opportunities generated by technology to data and information misuse, frauds, and resources misapplication and misappropriation. 
Appendix A.11. Propositions on Banking and Cryptocurrency: Eduardo Henrique Diniz

\section{Proposition A37. Growth in adoption of complementary cryptocurrencies.}

Comment: As a phenomenon known for decades and observed in different countries, complementary currencies are generally regarded as private and mostly non-regulated tools for fighting social exclusion and encouraging local development. While the emergency of the cryptocurrencies has become a particularly important case in the field of digital payments in general, it is also becoming a relevant subject for understanding the evolution of complementary currencies. Having reached a number of thousands of projects in the last few years, complementary currencies have also been characterized by a counter cyclical behavior, meaning that they tend to be adopted when economic crises arise and unemployment and a lack of access to the mainstream financial systems close the doors to the more vulnerable part of the population, reducing their level of adoption when the economic cycle rises up. This counter cyclical behavior can be observed by investigating the Swiss complementary currency known as Wirtschaftsring ("Economic Circle"), or simply WIR. Studies show that WIR, founded in 1934, is negatively correlated with GDP, what can be explained by the way individuals that are cash-short in a recession go more often after the use of WIR-credits. With the emergence of cryptocurrencies, the idea of dealing with alternative (and complementary) currencies in parallel with the fiat currencies become less exotic and not only restricted to the world of (systemic or eventual) underdeveloped economies. As technology behind cryptocurrencies (blockchain) is being also adopted by a number of more traditional complementary currencies, it is possible to expect that the use of complementary cryptocurrencies in the format of "neighborhood currencies" or "social currencies" will grow. As an unseen, i.e., phenomenon which causes unintended side effects, the emergence of cryptocurrencies, and its impact on the growth of complementary cryptocurrencies is largely underestimated and should deserve more attention from social scientists and economists.

Proposition A38. Emergence of crypto-engagement, type of social and citizen engagement based on cryptocurrencies adoption (Citizen crypto engagements).

Comment: The use of some type of monetary reward as a way to promote engagement (or fidelization) of a client with a particular service or product provider is somehow well known for decades. Rebates for buying in some stores, discounts in a second buy, milage programs, are all consolidated examples of the so called fidelization that create lock-in between the client and the provider, and in most cases are considered successful strategies, since both parts, buyer and seller, see advantages in adopting them. Less common than using monetary reward to promote engagement with clients is the use of monetary reward to promote engagement among citizens or with social causes, although some cases are worthwhile to mention. The Portuguese "lixo" (literally "garbage") is a parallel paper currency used in a neighborhood in Lisbon to "pay" citizens that contribute with the garbage collection. Citizens can use this payment in lixos to buy in the local commerce, that also see value in keeping the neighborhood clean, and to pay for transport, a service controlled at the city level. Another example is the e-portemonnee (e-wallet) designed to facilitate sustainable environmentally friendly behavior, rewarding participants for positive actions such as switching to a green energy provider or delivering goods to the local secondhand shop. E-portmonee credit is processed and stored in a central database where every user has his or her own electronic credit account and can be used to pay for other sustainable services or products. Nota Fiscal Paulista is another example from a state government in Brazil, whereby users that buy in a shop can ask for a credit related to a small percentage of his or her expending, and retrieve this credit later when paying for public services, such as some types of government taxes. All these initiatives could be better explored if they were converted into some type of cryptocurrency, what would make them more valuable for the users, that could be immediately available in their digital wallets and converted in benefits for them through their e-wallets, and also good for the currency issuer (usually a local government) that would have a better platform to control the issuance and circulation of these parallel currencies. 
Both sides, citizens and local governments, would benefit with a higher level of crypto-engagement. This is another unseen phenomenon that would deserve a better attention of social scientists through more in-depth research on these innovative ways to promote citizen engagement, or crypto-engagement.

Proposition A39. The challenge of expanding of stable cryptocurrencies that have prices tied to physical and/or stable values.

Comment: While most cryptocurrencies, such as the case of Bitcoin, are well known by their price volatility, stable cryptocurrencies are immune to the volatility of market-traded cryptocurrencies by pegging their value to a regular fiat currency, such as the USD, or even to stable physical unity, such as time or energy (kilowatt-hour). Although they are also built around the same technology of other cryptocurrencies (blockchain), they avoid unnecessary market risk either by adjusting the supply of the currency or by holding matching reserve assets in a fiat currency or other physical asset. A number of stable cryptocurrencies are being designed to promote local, social, or environmental development and are seen to be more acceptable for adoption by users, since most people feel more comfortable living in a world where monetary value is more stable over time. Some examples of this type of stable cryptocurrencies are: Liverpool Pound, Tel-Aviv Shekel, Plastic Bank, Faircoin, Moeda, and MonedaPar. Although still outnumbered by the more traditional volatile cryptocurrencies, stable cryptocurrencies could grow to become a more interesting model for those considering the implementation of complementary currencies. While most researchers are struggling to understand the market behavior of volatile currencies, the potential of stable cryptocurrencies remains mostly unseen within the academic world.

\section{References}

1. Linkov, I.; Trump, B.; Poinsatte-Jones, K.; Florin, M.V. Governance strategies for a sustainable digital world. Sustainability 2018, 10, 440. [CrossRef]

2. Scholz, R.W.; Bartelsman, E.J.; Diefenbach, S.; Franke, L.; Grunwald, A.; Helbing, D.; Hill, R.; Hilty, L.; Höjer, M.; Klauser, S.; et al. Unintended side effects of the digital transition: European scientists' messages from a proposition-based expert round table. Sustainability 2018, 10, 2001. [CrossRef]

3. Loebbecke, C.; Picot, A. Reflections on societal and business model transformation arising from digitization and big data analytics: A research agenda. J. Strateg. Inf. Syst. 2015, 24, 149-157. [CrossRef]

4. Heuvelink, G.B.M. Error Propagation in Environmental Modelling with GIS; CRC Press: London, UK, 1998.

5. Junkins, J.L.; Akella, M.R.; Alfriend, K.T. Non-Gaussian error propagation in orbital mechanics. Adv. Astronaut. Sci. 1996, 92, 283-298.

6. Wu, L.; Tan, X.; He, D.; Tian, F.; Qin, T.; Lai, J.H.; Liu, T.Y. Beyond error propagation in neural machine translation: Characteristics of language also matter. arXiv 2018, arXiv:1809.00120.

7. Sugiyama, M.; Deguchi, H.; Ema, A.; Kishimoto, A.; Mori, J.; Shiroyama, H.; Scholz, R.Z. Unintended side effects of digital transition: Perspectives of Japanese Experts. Sustainability 2017, 9, 2193. [CrossRef]

8. Scholz, R.W.; Viale-Pereira, G. Workbook for Preparing the South American Round Table Structuring Research on Sustainable Digital Environments Curitiba, August 9-10, 2018. Logistics - Schedule - Focus, Goals, Products - Rules of Discussion - Propositions- Glossary - Participants; Danube University of Krems: Krems, Austria, 2018.

9. Adger, W.N.; Brooks, N.; Bentham, G.; Agnew, M.; Eriksen, S. New Indicators of Vulnerability and Adaptive Capacity; University of East Anglia; NorwichTyndall Centre for Climate Change Research Norwich: Norwich, UK, 2005.

10. Scholz, R.W.; Blumer, Y.B.; Brand, F.S. Risk, vulnerability, robustness, and resilience from a decision-theoretic perspective. J. Risk Res. 2012, 15, 313-330. [CrossRef]

11. Pattberg, P.; Widerberg, O. Transnational multistakeholder partnerships for sustainable development: Conditions for success. Ambio 2016, 45, 42-51. [CrossRef]

12. Padmanabhan, M. (Ed.) Introduction: Transdisciplinarity for Sustainability, in Transdisciplinary Research and Sustainability; Routledge: London, UK, 2017; pp. 1-32. 
13. Scholz, R.W.; Kley, M.; Parycek, P. Reframing Global and European Digital Infrastructure as a Public Good!? Department of Knowledge and Information Management, Danube University Krems: Krems an der Donau, Austria, 2020; Unpublished work.

14. Scholz, R.W.; Steiner, G. The real type and ideal type of transdisciplinary processes: Part I-Theoretical foundations. Sustain. Sci. 2015, 10, 527-544. [CrossRef]

15. Scholz, R.W. Environmental Literacy in Science and Society: From Knowledge to Decisions; Cambridge University Press: Cambridge, UK, 2011.

16. Argyris, C. Double Loop Learning in Organizations. Harv. Bus. Rev. 1977, 55, 115-125.

17. Forrester, J.W. Principles of Systems: Text and Workbook; Wright-Allen-Press: Cambridge, MA, USA, 1968.

18. Helbing, D.; Frey, B.S.; Gigerenzer, G.; Hafen, E.; Hagner, M.; Hofstetter, Y.; Hoven, J.V.D.; Zicari, R.V.; Zwitter, A. Will Democracy Survive Big Data and Artificial Intelligence. Sci. Am. 2017, 25. Available online: https://www.scientificamerican.com/article/will-democracy-survive-big-data-and-artificialintelligence/ (accessed on 19 January 2020).

19. Zuboff, S. The Age of Surveillance Capitalism: The Fight for the Future at the New Frontier of Power; Profile Books: London, UK, 2019.

20. Helbing, D. The Automatization of Society is Next; Great Britain (Amazon): Dirk Helbing; CreateSpace Independent Publishing Platform: Scotts Valley, CA, USA, 2015.

21. Hobart, M.E.; Schiffman, Z.S. Information Ages: Literacy, Numeracy, and the Computer Revolution; John Hopkins University Press: Baltimore, MD, USA, 2000.

22. Berners-Lee, T.; Fischetti, M. Weaving the Web: The Original Design and Ultimate Destiny of the World Wide Web by its Inventor; DIANE Publishing Company: Darby, PA, USA, 2001.

23. Heylighen, F; Lenartowicz, M. The Global Brain as a model of the future information society: An introduction to the special issue. Technol. Forecast. Soc. Chang. 2017, 114, 1-6. [CrossRef]

24. Li, S.; Xu, L.D.; Zhao, S. 5G Internet of Things: A survey. J. Ind. Inf. Integr. 2018, 10, 1-9. [CrossRef]

25. Moy, P.; Hussain, M.M. Media and Public Opinion in a Fragmented Society, in the Spiral of Silence; Donsbach, W., Salmon, C.T., Tsfati, Y., Eds.; Routledge: London, UK, 2014; pp. 108-116.

26. Frey, C.B.; Osborne, M. The Future of Employment. How Susceptible are Jobs to Computerisation; University of Oxford: Oxford, UK, 2013.

27. Krausmann, F.; Gingrich, S.; Eisenmenger, N.; Erb, K.H.; Haberl, H.; Fischer-Kowalski, M. Growth in global materials use, GDP and population during the 20th century. Ecol. Econ. 2009, 68, 2696-2705. [CrossRef]

28. Steffen, W.; Richardson, K.; Rockström, J.; Cornell, S.E.; Fetzer, I.; Bennett, E.M.; Biggs, R.; Carpenter, S.R.; Vries, W.D.; Wit, C.A.D. Planetary boundaries: Guiding human development on a changing planet. Science 2015, 347. [CrossRef] [PubMed]

29. Velik, R. Quo Vadis, intelligent machine? BRAIN. Broad Res. Artif. Intell. Neurosci. 2010, 1, 13-22.

30. Vanparijs, P. Why surfers should be fed-The liberal case for an unconditional basic income. Philos. Public Aff. 1991, 20, 101-131.

31. Bidadanure, J.U. The political theory of universal basic income. Annu. Rev. Political Sci. 2019, 22, 481-501. [CrossRef]

32. Sahay, S.; Sein, M.K.; Urquhart, C. Flipping the context: ICT4D, the next grand challenge for IS research and practice. J. Assoc. Inf. Syst. 2017, 18, 837-847. [CrossRef]

33. Scholz, R.W.; Le, Q.L. Sustainable Phosphorus Management: A Global Transdisciplinary Roadmap; Scholz, R.W., Roy, A.H., Brand, F.S., Hellums, D.T., Ulrich, A.E., Eds.; Springer: Berlin, Germany, 2014; pp. 116-118.

34. Mingers, J.; Rosenhead, J. Problem structuring methods in action. Eur. J. Oper. Res. 2004, 152, 530-554. [CrossRef]

35. Eden, C.; Ackermann, F. Where next for problem structuring methods. J. Oper. Res. Soc. 2006, 57, 766-768. [CrossRef]

36. Rosenhead, J. Past, present and future of problem structuring methods. J. Oper. Res. Soc. 2006, 57, 759-765. [CrossRef]

37. Midgley, G.; Cavana, R.Y.; Brocklesby, J.; Foote, J.L.; Wood, D.R.R.; Ahuriri-Driscoll, A. Towards a new framework for evaluating systemic problem structuring methods. Eur. J. Oper. Res. 2013, 229, 143-154.

38. Scholz, R.W.; Spoerri, A.; Lang, D.J. Problem structuring for transitions: The case of Swiss waste management. Futures 2009, 41, 171-181. [CrossRef] 
39. Scholz, R.W.; Czichos, R.; Parycek, P.; Lampoltshammer, T.J. Organizational vulnerability of digital threats: A first validation of an assessment method. Eur. J. Oper. Res. 2020, 282, 627-643. [CrossRef]

40. Renn, O.; Scholz, R.W. The Unintended Side Effects of Digitalization. DiDaT: The Responsible of Use Digital Data as the Focus of a New Transdisciplinary Project; IASS: Potsdam, Germay, 2018. [CrossRef]

41. Bellman, R. Artificial Intelligence: Can Computers Think; Thomson Course Technology: Boston, MA, USA, 1978.

42. Merten, K. Inhaltsanalyse: Einführung in Theorie, Methode und Praxis; Springer: Wiesbaden, Germany, 2013.

43. Walsham, G. ICT4D research: Reflections on history and future agenda. Inf. Technol. Dev. 2017, $23,18-41$. [CrossRef]

44. Montag, C.; Diefenbach, S. Towards Homo Digitalis: Important Research Issues for Psychology and the Neurosciences at the Dawn of the Internet of Things and the Digital Society. Sustainability 2018, 10, 415. [CrossRef]

45. Bennett, W.L.; Segerberg, A. The logic of connective action: Digital media and the personalization of contentious politics. Inf. Commun. Soc. 2012, 15, 739-768. [CrossRef]

46. Melo, F.L.N.B.D.; Sampaio, L.M.B.; Oliveira, R.L.D. Bureaucratic Corruption and Entrepreneurship: An. Empirical Analysis of Brazilian States. Rev. Adm. Contemp. 2015, 19, 374-397. [CrossRef]

47. Luciano, E.M.; Scholz, R.W. The Unintended Side Effects of Digitalization. MitiCo: Mitigating Corruption in Brazil through a Transdisciplinaty Analysis; PUCRS: Porto Alegre, Brazil, 2019.

48. Rosenhead, J.; Mingers, J. Rational Analysis for a Problematic World Revisited; John Wiley: New York, NY, USA, 2001.

49. Scholz, R.W.; Steiner, G. Transdisciplinarity at the crossroads. Sustain. Sci. 2015, 10, 521-526. [CrossRef]

50. Pereira, G.V.; Parycek, P.; Falco, E.; Kleinhans, R. Smart governance in the context of smart cities: A literature review. Inf. Polity 2018, 23, 143-162. [CrossRef]

51. ITU. ITU Releases 2018 Global and Regional ICT Estimates. 2018. Available online: https://www.itu.int/en/ mediacentre/Pages/2018-PR40.aspx (accessed on 27 November 2019).

52. ITU. Measuring the Information Society Report 2017; International Telecommunication Union (ITU): Geneva, Switzerland, 2017; Volume 1.

53. Bertot, J.C.; Estevez, E.; Janowski, T. Universal and contextualized public services: Digital public service innovation framework. Gov. Inf. Q. 2016, 33, 211-222. [CrossRef]

54. Ryznar, M. Protecting Users of Social Media. Notre Dame Law Rev. Online, Notre Dame 2019. Available online: https://scholarship.law.nd.edu/cgi/viewcontent.cgi?article=1067\&context=ndlr_online (accessed on 27 November 2019).

55. Gurstein, M.B. Open data: Empowering the empowered or effective data use for everyone? First Monday 2011, 16, 1-9. [CrossRef]

56. Tufekci, Z. Social movements and governments in the digital age: Evaluating a complex landscape. J. Int. Aff. 2014, 68, 1-18.

57. Matz, S.; Rolnik, G.; Cerf, M. Solutions to the Threats of Digital Monopolies. In Digital Platforms and Concentration; ProMarket: Chicago, IL, USA, 2018.

58. Luca, M.; Wu, T.; Couvidat, S.; Frank, D.; Seltzer, W. Does Google Content Degrade Google Search? Experimental Evidence; Working Paper 16-035; Harvard Business School: Boston, MA, USA, 2015.

59. Filippi, P.D.; Vieira, M.S. The Commodification of Information Commons: The case of cloud computing. Technol. Law Rev. 2014, 16, 102-143.

60. UN ECLAC. Estado de la Banda Ancha en América Latina y el Caribe 2016; United Nations Economic Commission for Latin America and the Caribbean: Santiago, Chile, 2016; p. 46.

61. Sierra, C.; Botti, V.; Ossowski, S. Agreement Computing. KI Künstliche Intell. 2011, 25, 57-61. [CrossRef]

62. Chesñevar, C.; Onaindia, E.; Ossowski, S.; Vouros, G. (Eds.) Special issue on agreement technologies. Inf. Syst. Front. 2015, 17, 707-711. [CrossRef]

63. Chesñevar, C.; Maguitman, A.; González, M. Empowering recommendation technologies through argumentation. In Argumentation in Artificial Intelligence Chapter 20; Springer: Berlin, Germany, 2009; pp. 403-422.

64. Anandhan, A.; Shuib, L.; Ismail, M.A.; Mujtaba, G. Social Media Recommender Systems: Review and Open Research Issues. IEEE Access 2018, 6, 15608-15628. [CrossRef]

65. Heras, S.; Palanca, J.; Chesñevar, C. Argumentation-based Personal Assistants for Ambient Assisted Living. In Personal Assistants: Emerging Computational Technologies; Costa, A., Julian, V., Novais, P., Eds.; Intelligent Systems Reference Library; Springer: Berlin, Germany, 2018; Volume 132, pp. 19-36. 
66. Mohammadi, M.; Al-Fuqaha, A. Enabling Cognitive Smart Cities Using Big Data and Machine Learning: Approaches and Challenges. IEEE Commun. Mag. 2018, 56, 94-101. [CrossRef]

67. Vishwanath, R.; Hulipalled, R.; Venugopal, K.; Patnaik, L. Consumer insight mining: Aspect based Twitter opinion mining of mobile phone reviews. Appl. Soft Comput. 2018, 68, 765-773.

68. Yu, H.; Shen, Z.; Miao, C.; Leung, C.; Lesser, V.; Yang, Q. Building Ethics into Artificial Intelligence. IJCAI 2018, 5527-5533.

69. Kirkpatrick, K. The moral challenges of driverless cars. Commun. ACM 2015, 58, 19-20. [CrossRef]

70. Langley, P.; Meadows, B.; Sridharan, M.; Choi, D. Explainable Agency for Intelligent Autonomous Systems; IAAI: Westchester, IL, USA, 2017; pp. 4762-4763.

71. Avgerou, C.; Walsham, G. Introduction: IT in developing countries. Inf. Technol. Context Stud. Perspect. Dev. Ctries. 2000, 1, 1-7.

72. Avgerou, C. The link between ICT and economic growth in the discourse of development. In Organizational Information Systems in the Context of Globalization; Springer: Boston, MA, USA, 2003; pp. 373-386.

73. Macadar, M.A.; Reinhard, N. Telecentros comunitários possibilitando a inclusão digital: Um estudo de caso comparativo de iniciativas brasileiras. Anais do 26 ENANPAD. 2002. Available online: http: //www.anpad.org.br/admin/pdf/enanpad2002-adi-1296.pdf (accessed on 19 January 2020).

74. Silva, L.; Figueroa, B.E. Institutional intervention and the expansion of ICTs in Latin America: The case of Chile. Inf. Technol. People 2002, 15, 8-25. [CrossRef]

75. Joia, L.A.; Zamot, F. Internet-Based Reverse Auctions by the Brazilian Government. Electron. J. Inf. Syst. Dev. Ctries 2002, 9, 1-12. [CrossRef]

76. Galperin, H.; Mariscal, J. (Eds.) Digital Poverty: Latin American and Caribbean Perspectives; IDRC: Ottawa, ON, Canada, 2007.

77. Santos, R.P.; Joia, L.A. Agência Barco e a Inclusão Ffinanceira da População Ribeirinha da Ilha de Marajó. e populações ribeirinhas: Avaliação de impacto da Agência Barco. Rev. Adm. Pública 2017, 52, 650-675. [CrossRef]

78. Rodríguez, G.R. Information and Communication Technologies and Non-Governmental Organisations: Lessons Learnt from Networking in Mexico. Electron. J. Inf. Syst. Dev. Ctries 2005, 21, 1-29. [CrossRef]

79. Escobar, A. Encountering Development: The Making and Unmaking of the Third World. Princeton Studies in Culture/Power/History; Princeton University Press: Princeton, NJ, USA, 1995.

80. Sen, A.K. Development as Freedom; Oxford University Press: Oxford, UK, 2001.

81. Joia, L.A. Bridging the digital divide: Some initiatives in Brazil. Electron. Gov. Int. J. 2004, 1, $300-315$. [CrossRef]

82. Pereira, M.A. Internet e mobilização política: Os movimentos sociais na era digital. Encontro Compolítica 2011, 4, 1-26.

83. Castells, M. Communication Power; OUP Oxford: Oxford, UK, 2013.

84. Lugão, A.C.; Santana, E.; Ferrari, M.; de Jesus, D.S.V. Conselho europeu: Austeridade, estabilidade e crescimento-Novos acordos em tempos de crise. Modelo Intercolegial de Relações Internacionais. 2014. Available online: http://ptdocz.com/doc/190832/conselho-europeu--austeridade (accessed on 1 August 2018).

85. Ramos, A.; Oliveira, R. Indivíduos, sociedade, tecnologia: As manifestações nas ruas das cidades brasileiras e as redes sociais. Rev. Tecnol. Soc. 2014, 10, 176-187. [CrossRef]

86. Joia, L.A. Social Media and the "20 Cents Movement" in Brazil: What Lessons Can Be Learnt from This? Inf. Technol. Dev. 2016, 22, 422-435. [CrossRef]

87. Castells, M. A Galáxia Internet: Reflexões Sobre a Internet, Negócios e a Sociedade; Oxford University Press: Oxford, UK, 2003.

88. Passini, S. The facebook and Twitter revolutions: Active participation in the 21st century. Hum. Aff. 2012, 22, 301-312. [CrossRef]

89. Shirky, C. The political power of social media: Technology, the public sphere, and political change. Foreign Aff. 2011, 90, 28-41.

90. Papic, M.; Noonan, S. Social media as a tool for protest. Stratf. Glob. Intell. 2011, 3, 1-7.

91. Chae, M.S.; Yeum, D.S. The impact of mobile technology paradox perception and personal risk-taking behaviors on mobile technology adoption. Manag. Sci. Financ. Eng. 2010, 16, 115-138.

92. Yuan, Y.; Archer, N.; Connelly, C.E.; Zheng, W. Identifying the ideal fit between mobile work and mobile work support. Inf. Manag. 2010, 47, 125-137. [CrossRef] 
93. Oulasvirta, A.; Rattenbury, T.; Ma, L.; Raita, E. Habits make smartphone use more pervasive. Pers. Ubiquitous Comput. 2012, 16, 105-114. [CrossRef]

94. Borges, A.P.; Joia, L.A. Executives and smartphones: An ambiguous relationship. Manag. Res. Rev. 2013, 36, 1167-1182. [CrossRef]

95. Borges, A.P.; Joia, L.A. Paradoxes perception and smartphone use by Brazilian executives: Is this genderless? J. High Technol. Manag. Res. 2015, 26, 205-218. [CrossRef]

96. Barjis, J.; Gupta, A.; Sharda, R. Knowledge work and communication challenges in networked enterprises. Inf. Syst. Front. 2011, 13, 615-619. [CrossRef]

97. Clegg, S.R.; da Cunha, J.V.; Cunha, M.P. Management paradoxes: A relational view. Hum. Relat. 2002, 55, 483-503. [CrossRef]

98. Mick, D.G.; Fournier, S. Paradoxes of technology: Consumer cognizance, emotions, and coping strategies. J. Consum. Res. 1998, 25, 123-143. [CrossRef]

99. Beaudry, A.; Pinsonneault, A. Understanding user responses to information technology: A coping model of user adaptation. MIS Q. 2005, 29, 493-524. [CrossRef]

100. Bolívar, M.P.R. Characterizing the role of governments in smart cities: A literature review. In Smarter as the New Urban; Gil-Garcia, J.R., Pardo, T.A., Nam, T., Eds.; Springer: Berlin, Germany, 2016; pp. 49-71.

101. Diniz, E.H.; Barbosa, A.F.; Junqueira, A.R.B.; Prado, O. O governo eletrônico no Brasil: Perspectiva histórica a partir de um modelo estruturado de análise. Rev. Adm. Pública 2009, 43, 23-48. [CrossRef]

102. Cunha, M.A.; Miranda, P.D.M. A pesquisa no uso e implicações sociais das tecnologias da informação e comunicação pelos governos no Brasil: Uma proposta de Agenda a partir de reflexões da prática e da produção acadêmica nacional. OES-Organizações \& Sociedade 2008, 66, 543-566.

103. CGI, Comitê Gestor da Internet no Brasil. Pesquisa Sobre o uso de Tecnologias de Informação e Comunicação no Brasil, TIC Governo Eletrônico 2017; Comitê Gestor da Internet no Brasil: São Paulo, Brasil, 2018.

104. Przeybilovicz, E.; Cunha, M.A.; Meirelles, F. The use of information and communication technology to characterize municipalities: Who they are and what they need to develop e-government and smart city initiatives. Braz. J. Public Adm. 2018, 52, 630-649.

105. Angelidou, M. Smart city policies: A spatial approach. Cities 2014, 41, 3-11. [CrossRef]

106. Glass, R. Aspects of change. In The Gentrification Debates A Reader; Routledge: Oxfordshire, UK, 1964; pp. 19-30.

107. Smith, N. New globalism, new urbanism: Gentrification as global urban strategy. Antipode 2002, 34, 427-450. [CrossRef]

108. Albuquerque, J.P.D.; Almeida, A.A.D. Modes of engagement: Constitutive tensions in citizen sensing and volunteered geographic information. In Mah et al. (Forthcoming), Environmental Justice and Citizen Science in a Post Truth Age; Manchester University Press: Manchester, UK, 2018.

109. UN-Habitat. Urbanization and Development: Emerging Futures. In World Cities Report 2016; UN-Habitat: Nairobi, Kenya, 2016.

110. Townsend, A.M. Smart Cities: Big Data, Civic Hackers, and the Quest for a New Utopia; WW Norton \& Company: New York, NY, USA, 2013.

111. Chui, M.; Lund, S.; Madgavkar, A.; Mischke, J.; Ramaswamy, S. Smart Cities: Digital Solutions for a More Livable Future; McKinsey\&Company: New York, NY, USA, 2018.

112. Mah, A. Environmental justice in the age of big data: Challenging toxic blind spots of voice, speed, and expertise. Environ. Sociol. 2017, 3, 122-133. [CrossRef]

113. Haklay, M. Neogeography and the delusion of democratisation. Environ. Plan. A 2013, 45, 55-69. [CrossRef]

114. Dourish, P. The Internet of Urban Things. In Code and the City; Kitchin, R., Perng, Y.S., Eds.; Routledge: London, UK, 2016; pp. 27-48.

115. Gabrys, J. Program Earth—Environmental Sensing Technology. Minneapolis; University of Minnesota Press: London, UK, 2016.

116. Perkins, C. Plotting practices and politics: (im)mutable narratives in OpenStreetMap. Trans. Inst. Br. Geogr. 2014, 39, 304-317. [CrossRef]

117. Frey, C.B.; Osborne, M.A. Technology at Work v2.0: The future is not what it used to be. CITI GPS Global Perspectives E Solutions, 26 January 2016.

118. De Groen, W.P.; Lenaerts, K.; Bosc, R.; Paquier, F. Impact of Digitalisation and the on-Demand Economy on Labour Markets and the Consequences for Employment and Industrial Relations. Final Study. CEPS Special 
Report, August 2017. Policy Paper. Available online: https://www.eesc.europa.eu/resources/docs/qe-02-17763-en-n.pdf (accessed on 1 August 2018).

119. Hüsing, T.; Korte, W.B.; Dashja, E. E-Skills \& Digital Leadership Skills Labour Market in Europe 2015-2020. empirica Schriftenreihe Nr 2/2016. 2016. Available online: https://epale.ec.europa.eu/en/resource-centre/ content/e-skills-europe-trends-and-forecasts-european-ict-professional-and-digital (accessed on 1 August 2018).

120. Rodrik, D. Premature Deindustrialization. National Bureau of Economic Research, No. w20935. 2015. Available online: https://www.nber.org/papers/w20935 (accessed on 1 August 2018).

121. Jerome, J. Buying and Selling Privacy: Big Data's Different Burdens and Benefits. Stanford Law. 2013. Available online: https://www.stanfordlawreview.org/online/privacy-and-big-data-buying-and-sellingprivacy/ (accessed on 1 August 2018).

122. Katz, R. Social and Economic Impact of Digital Transformation on the Economy; GSR-17 Discussion Paper; ITU: Pairs, France, 2017.

123. Baker, D. The Opportunities and Risks of the Sharing Economy; Testimony before the Subcommittee on Commerce, Manufacturing, and Trade of the US House of Representatives Committee on Energy and Commerce: Washington, DC, USA, 2015.

124. Kergroach, S. Industry 4.0: New Challenges and Opportunities for the Labour Market. Foresight STI Gov. 2017, 11, 6-8. [CrossRef]

125. Porter, M.E. The Competitive Advantage of Nations. Harvard Bus. Rev. 1990, 73-93.

126. Assis, L.F.; Fujiwara, L.; Vilela, R.A.G.; Cardoso, M.R.A. Observatório Digital de Saúde e Segurança do Trabalho (MPT-OIT). In Dicionário de saúde e segurança do trabalhador: Conceitos, definições, história, cultura; Mendes, R., Ed.; Proteção Publicações Ltda: Novo Hamburgo, Brazil, 2018.

127. Ministério da Fazenda, Secretaria de Previdência, Empresa de Tecnologia e Informações da Previdência. Anuário Estatístico da Previdência Social-Ano 2016. Brasília: MF/DATAPREV; 2017. Available online: http://sa.previdencia.gov.br/site/2018/08/aeps2016.pdf (accessed on 15 January 2020).

128. Ilmarinen, J. Towards a Longer Worklife! Ageing and the Quality of Worklife in the European Union; Finnish Institute of Occupational Health: Helsinki, Finnish, 2006.

129. Morschhäuser, M.; Sochert, R. Healthy Work in an Ageing Europe: Strategies and Instruments for Prolonging Working Life. European Network for Workplace Health Promotion. 2008. Available online: http://www. ageingatwork.eu/resources/health-work-in-an-ageing-europe-enwhp-3.pdf (accessed on 1 August 2018).

130. Brasil. Lei $\mathrm{n}^{\circ} 13.467$, de 13 de julho de 2017. Altera a Consolidação das Leis do Trabalho (CLT), aprovada pelo Decreto-Lei no 5.452, de 1o de maio de 1943, e as Leis nos 6.019, de 3 de janeiro de 1974, 8.036, de 11 de maio de 1990, e 8.212, de 24 de julho de 1991, a fim de adequar a legislação às novas relações de trabalho. Diário Oficial da União. 14 jul 2017. Available online: http://www.planalto.gov.br/ccivil_03/_ato2015-2018/ 2017/lei/113467.htm (accessed on 1 August 2018).

131. Brasil. Câmara dos Deputados. Comissão de Constituição e Justiça e de Cidadania (CCJC). Proposta de Emenda à Constituição 287, de 08 de dezembro de 2016. Altera os arts. 37, 40, 109, 149, 167, 195, 201 e 203 da Constituição, para dispor sobre a seguridade social, estabelece regras de transição e dá outras providências. Available online: http://www.camara.gov.br/proposicoesWeb/prop_mostrarintegra?codteor= 1514975\&filename $=$ PEC+287/2016 (accessed on 1 August 2018).

132. Brasil. Decreto no. 8373, de 11 de dezembro de 2014. Institui o Sistema de Escrituração Digital das Obrigações Fiscais, Previdenciárias e Trabalhistas - eSocial e dá outras providências. Diário Oficial da União. 12 dez 2014. Available online: http://www.planalto.gov.br/ccivil_03/_ato2011-2014/2014/decreto/d8373.htm (accessed on 1 August 2018).

133. Cardona, D.; Serida-Nishimura, J. The Peruvian Citizen Perception and Expectation toward the e-government. The Electronic Tax Payment as a Successful e-Gov Project; Revista Universidad y Empresa, Facultad de Administración Universidad del Rosario: Bogota, Colombia, 2006; Volume 8, pp. 142-158.

134. Cardona, D.; López-Bachiller, J.; Saenz-Core, J. ICT for development and the MuNet program: Experiences and lessons learnt from an indigenous municipality in Guatemala. In Proceedings of the 6th International Conference on Theory and Practice of Electronic Governance ACM International Conference Proceeding Series, Macao, China, 10-13 December 2012; pp. 188-191, ISBN 978-1-4503-1200-4. Available online: http://dl.acm.org/citation.cfm?doid=2463728.2463767 (accessed on 1 August 2018). 
135. Treré, E. The Dark Side of Digital Politics: Understanding the Algorithmic Manufacturing of Consent and the Hindering of Online Dissidence. Open. Govern. 2016, 47, 1. [CrossRef]

136. Huang, M.-H.; Hong, W. Digital Revolution or Digital Dominance? Regime Type, Internet Control, and Political Activism in East Asia. Korean J. Int. Stud. 2017, 15, 219-245. [CrossRef]

137. Jost, J.T.; Barberá, P.; Bonneau, R.; Langer, M.; Metzger, M.; Nagler, J.; Sterling, J.; Tucker, J.A. How Social Media Facilitates Political Protest: Information, Motivation, and Social Networks. Political Psychol. 2018, 39, 85-118. [CrossRef]

138. Sunstein, C.R. \#Republic: Divided Democracy in the Age of Social Media; Princeton University Press: Princeton, NJ, USA, 2018.

139. Krämer, B. Populist online practices: The function of the Internet in right-wing populism. Inf. Commun. Soc. 2017, 20, 1293-1309. [CrossRef]

140. Cardona, D.; Cortés, J.; Ujueta, S. Gobierno Electrónico en Colombia: Marco normativo y evaluación de tres índices estratégicos. Revista Venezolana de Gerencia, 2015, No. 20 (January-March). Available online: http://www.redalyc.org/articulo.oa?id=29036968002 (accessed on 25 July 2018).

141. Carr, I.; Jago, R. Petty Corruption, Development and Information Technology as an Antidote. Round Table 2014, 103, 465-482. [CrossRef]

142. Gauld, R.; Goldfinch, S.; Horsburgh, S. Do they want it? Do they use it? The 'Demand-Side' of e-Government in Australia and New Zealand. Gov. Inf. Q. 2010, 27, 177-186. [CrossRef]

143. Chesbrough, H. Business model innovation: It's not just about technology anymore. Strat. Leadersh. 2007, 35, 12-17. [CrossRef]

144. Nfuka, E.; Rusu, L.; Johannesson, P.; Mutagahywa, B. The State of IT Governance in Organizations from the Public Sector in a Developing Country. In Proceedings of the Institute of Electrical and Electronics Engineers (IEEE) 2009 42nd Hawaii International Conference on System Sciences, Waikoloa, HI, USA, 5-8 January 2009; pp. 1-12.

145. Blackburn, K.; Forgues-Puccio, G.F. Why is corruption less harmful in some countries than in others? J. Econ. Behav. Organ. 2009, 72, 797-810. [CrossRef]

146. Dreher, A.; Gassebner, M. Greasing the wheels? The impact of regulations and corruption on firm entry. Public Choice 2013, 155, 413-432. [CrossRef]

147. World Bank Group. Ease of Doing Business Ranking. 2018. Available online: http://www.doingbusiness.org (accessed on 9 April 2018).

148. Transparency International. Corruption Perception Index. 2017. Available online: https://www.transparency. org/ (accessed on 3 March 2018).

149. Holmemo, M.D.Q.; Ingvaldsen, J.A. Local adaption and central confusion: Decentralized strategies for public service Lean implementation. Public Money Manag. 2018, 38, 13-20. [CrossRef]

150. Del Monte, A.; Papagni, E. Public expenditure, corruption, and economic growth: The case of Italy. Eur. J. Politi Econ. 2001, 17, 1-16. [CrossRef]

151. Power, T.J.; González, J. Cultura política, capital social e percepções sobre corrupção: Uma investigação quantitativa em nível mundial. Rev. Sociol. Política 2003, 21, 51-69. [CrossRef]

152. Carraro, A.; Menezes, G.R.; Canever, M.D.; Fernandez, R.N. Formação de Empresas e Corrupção: Uma Análise para os Estados Brasileiros; Encontro de Economia da Região Sul - ANPEC/SUL: Florianópolis, Santa Catarina, Brasil, 2011.

153. Bertot, J.C.; Jaeger, P.T.; Grimes, J.M. Using ICTs to create a culture of transparency: E-government and social media as openness and anti-corruption tools for societies. Gov. Inf. Q. 2010, 27, 264-271. [CrossRef]

154. Bailard, C.S. Mobile Phone Diffusion and Corruption in Africa. Politi Commun. 2009, 26, 333-353. [CrossRef]

155. Haafst, R. On The Effect of Digital Transformation on Corruption; KU Leuven: Leuven, Belgium, 2017. [CrossRef]

156. Shim, D.C.; Eom, T.H. E-Government and Anti-Corruption: Empirical Analysis of International Data. Int. J. Public Adm. 2008, 31, 298-316. [CrossRef]

157. Ionescu, L. E-Government and Social Media as Effective Tools in Controlling Corruption in Public Administration. Econ. Manag. Financ. Mark. 2016, 11, 66-72.

(C) 2020 by the authors. Licensee MDPI, Basel, Switzerland. This article is an open access article distributed under the terms and conditions of the Creative Commons Attribution (CC BY) license (http://creativecommons.org/licenses/by/4.0/). 